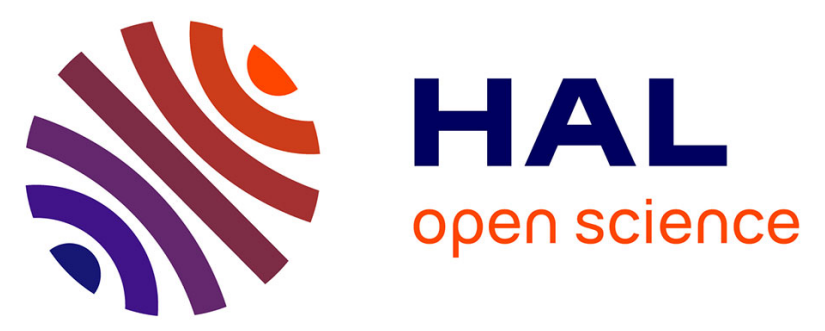

\title{
Interactions of oxygen with intrinsic defects in L1 0 $\gamma$-TiAl in presence of substitutional solutes: influence on diffusion kinetics
}

Camille Thenot, Rémy Besson, Pierre Sallot, Jean-Philippe Monchoux, Damien Connétable

\section{To cite this version:}

Camille Thenot, Rémy Besson, Pierre Sallot, Jean-Philippe Monchoux, Damien Connétable. Interactions of oxygen with intrinsic defects in L1 $0 \gamma$-TiAl in presence of substitutional solutes: influence on diffusion kinetics. Computational Materials Science, 2021, 201, pp.110933. 10.1016/j.commatsci.2021.110933 . hal-03370406

\section{HAL Id: hal-03370406 \\ https://hal.science/hal-03370406}

Submitted on 8 Oct 2021

HAL is a multi-disciplinary open access archive for the deposit and dissemination of scientific research documents, whether they are published or not. The documents may come from teaching and research institutions in France or abroad, or from public or private research centers.
L'archive ouverte pluridisciplinaire HAL, est destinée au dépôt et à la diffusion de documents scientifiques de niveau recherche, publiés ou non, émanant des établissements d'enseignement et de recherche français ou étrangers, des laboratoires publics ou privés. 


\title{
Interactions of oxygen with intrinsic defects in $L 1_{0} \gamma$-TiAl in presence of substitutional solutes: influence on diffusion kinetics
}

\author{
Camille Thenot, ${ }^{1,2}$ Rémy Besson,${ }^{3}$ Pierre Sallot,${ }^{4}$ Jean-Philippe Monchoux, ${ }^{2}$ and Damien Connétable ${ }^{1, *}$ \\ ${ }^{1}$ CIRIMAT, CNRS, Toulouse, France, CIRIMAT-ENSIACET, \\ 4 allée Émile Monso, BP 44362, F-31030 Toulouse Cedex 4, France \\ ${ }^{2}$ CEMES CNRS UPR 8011, 29 Rue Jeanne Marvig, F-31055 Toulouse, France \\ ${ }^{3}$ Univ. Lille, CNRS, INRAE, Centrale Lille, UMR 8207 - UMET - Unité Matériaux et Transformations, F-59000 Lille, France \\ ${ }^{4}$ Safran Tech, Magny les hameaux Cedex, France
}

(Dated: September 26, 2021)

\begin{abstract}
This work reexamines the insertion of $\mathrm{O}$ atoms in the $L 1_{0} \gamma$-TiAl system using first-principles calculations and thermodynamic modeling in the independent point defect approximation. It includes a study of intrinsic point defects, the insertion of many alloying elements (more than twenty were considered), as well as a study of their interaction with oxygen. The formation of complex defects composed of either vacancies, anti-sites or solute elements is then studied. Results at the atomic scale show a high segregation of oxygen in titanium-rich environments: oxygen easily segregates onto $\mathrm{Ti}$ anti-sites $\left(\mathrm{Ti}_{\mathrm{Al}}\right)$ and alloying elements are located in the vicinity of $\mathrm{Al}$ sub-lattices. DFT point-defect energetics shows that there is a clear correlation between the nature and site preference of an alloying element, and the oxygen segregation energy in the vicinity of this solute. The thermodynamic model shows that at equilibrium, oxygen does not occupy isolated interstitial sites but prefers to be located in the vicinity of $\mathrm{Ti}$ anti-sites or alloying elements. The effect of this strong segregation on oxygen diffusivity is discussed hereinafter. Results show a strong slowdown in oxygen diffusivity due to intrinsic defects. For $\mathrm{Ti} / \mathrm{Al}>0.5$ ratios, the traps for $\mathrm{O}$ diffusion are mainly constituted by $\mathrm{Ti}$ anti-sites, and the addition of solutes does not contribute much to the trapping of diffusing $\mathrm{O}$ atoms. For $\mathrm{Ti} / \mathrm{Al}<0.5$ ratios however, the contribution of solutes to trapping phenomena can be very important, and a decrease by 1-2 orders of magnitude of effective $\mathrm{O}$ diffusion coefficients can be observed for temperatures around 800-1100 K.
\end{abstract}

\section{INTRODUCTION}

Oxygen in solid solution has long been known for its significant impact on the mechanical properties of TiAl alloys. Because these materials are now implemented in hot parts of aeronautical and automotive engines, the issue of the dependence of the mechanical properties of $\mathrm{TiAl}$ alloys on $\mathrm{O}$ concentration is becoming increasingly a concern. However, due to the low solubility of $\mathrm{O}$ in the $\gamma$ phase, which in most cases represents the main volume fraction in these alloys, the experimental investigation of these phenomena is difficult, but theoretical approaches can provide interesting guidelines.

The effect of $\mathrm{O}$ on mechanical properties has been observed experimentally either when $\mathrm{O}$ is initially dissolved in the material, or when $\mathrm{O}$ penetrates into it by diffusion. In the case where $\mathrm{O}$ is initially present in the material as a contaminant, even though this problem is well known in the casting industry, only a few works studied this effect, due to the difficulty of elaborating high-purity, uncontaminated materials Nevertheless, some studies unambiguously showed that ductility decreases as the concentration of dissolved $\mathrm{O}$ rises $[1,2]$. To explain these changes in mechanical properties different interpretations have been proposed. Some studies pointed out the probable role of dissolved oxygen in reducing the mobility of ordinary dislocations $[3,4]$. Other works, based on TEM

\footnotetext{
* damien.connetable@ensiacet.fr
}

observations, highlighted the influence of extrinsic pinning points anchoring the dislocations $[5,6]$, which could be constituted by O-rich atomic precipitates [7]. Finally, some studies hypothesized the formation of nanometric O-rich precipitates (of about $5-10 \mathrm{~nm}$ in size) [8], presumably composed of $\mathrm{Al}_{2} \mathrm{O}_{3}$ [9], that could interact with the dislocations, and thus increase yield stress.

The other phenomenon that causes a reduction in ductility is when the alloys are submitted to heat treatments in air at high temperature $\left(300-800^{\circ} \mathrm{C}\right)$, for 10 $100 \mathrm{~h}$. In that case, a significant decrease in ductility at room temperature is observed [10-17]. To account for this phenomenon, the formation of a brittle surface layer $[10,12,15]$, was proposed, but the underlying mechanisms remain largely obscure. However, though the precise mechanism leading to ductility loss has not been clearly revealed yet, it is very likely that $\mathrm{O}$ diffusion plays a significant role in it $[14,16,17]$.

To further interpret these phenomena, a key question is to determine the concentration of $\mathrm{O}$ in the $\gamma$ phase. Measurements were thus carried out by atom probe tomography in a $\mathrm{Ti}_{52} \mathrm{Al}_{48}$ alloy [18]. On average, the $\mathrm{O}$ concentration was of about 2300 at. ppm in the bulk. In the $\gamma$ phase however, it was of 230 at. ppm only, most of the $\mathrm{O}$ partitioning to the $\alpha_{2}$ phase, in which the $\mathrm{O}$ content was 19200 at. ppm. Because the volume fraction of the $\alpha_{2}$ phase amounted to $10 \%$, this concentration was in quantitative agreement with the average bulk $\mathrm{O}$ concentration of the sample. In other words, most of the oxygen dissolved in the bulk was actually in 
the $\alpha_{2}$ phase. The fact that $\mathrm{O}$ solubility is much higher in $\alpha_{2}$ than in $\gamma$ can be explained by the chemical environment, rather than by size effects: in $\alpha_{2}$, there exist Ti-rich sites composed of $6 \mathrm{Ti}$ atoms surrounding octahedral cavities, whereas there are none in $\gamma$ [19]. Based on atom probe experiments, the same study showed that the solubility of $\mathrm{O}$ was stable in the $\gamma$ phase up to ageing temperatures of $1300^{\circ} \mathrm{C}$. However, the structure and the thermodynamical stability of this solid solution remains largely unknown. In particular, the interactions of dissolved $\mathrm{O}$ with the various point defects, such as vacancies, anti-sites, and substitutional solutes, have not been established. A better understanding of these phenomena could help describe the structure and chemistry of these complex point defects, which could act either as pinning points for the dislocations, and/or traps for the diffusing O solutes.

Due to the low solubility of $\mathrm{O}$ in the $\gamma$ phase, its diffusivity remains largely unknown. Some data concerning the diffusion coefficients of $\mathrm{O}$ in the $\alpha_{2}$ phase are available, with however significant discrepancy [20, 21]. At $800^{\circ} \mathrm{C}$ for example, values of $4-6 \times 10^{-18} \mathrm{~m}^{2} / \mathrm{s}$ [21] and $1.1 \times 10^{-16} \mathrm{~m} 2 / \mathrm{s}[20]$, are reported. Regarding $\gamma-\mathrm{TiAl}$, measurements were carried out in amorphous TiAl layers deposited in sputtering experiments and gave values of around $10^{-14} \mathrm{~m}^{2} / \mathrm{s}$ at $700^{\circ} \mathrm{C}[22]$. To the authors' knowledge, these are the only experimental data that can be found in the literature. However, O diffusion coefficients were determined theoretically in three separate studies and results were comparable [23-26]. Surprisingly, these works all predict values that are quite high (in the order of $10^{-11} \mathrm{~m}^{2} / \mathrm{s}$ at $700^{\circ} \mathrm{C}$, for a diffusion perpendicular to the [001] crystalline axis). These studies also predict an anisotropy of the diffusion coefficient, the value parallel to the [001] crystalline axis being about one order of magnitude smaller than the value perpendicular to [001]. The theoretical activation energies from the three studies are also close, about 1.1-1.2 eV perpendicular to the [001] direction, and $1.2 \mathrm{eV}$ parallel to [001]. However, none of these previous works evaluated the effect of substitutional solutes on $\mathrm{O}$ diffusivity, like $\mathrm{Cr}, \mathrm{Nb}, \mathrm{W}, \mathrm{Mo}$, etc., which are generally added to TiAl alloys.

Therefore, studying thoroughly the coupling between (i) addition of solutes and (ii) solubility and diffusion kinetics of $\mathrm{O}$ in the $\gamma$-TiAl phase is important for developing these alloys. However, investigating these issues is difficult because of the very low solubility of $\mathrm{O}$ in the $\gamma$ phase of TiAl. Consequently, theoretical approaches are interesting tools when studying dissolution and diffusion phenomena. This reason motivated the present study as it addresses the thermodynamical stability of complex point defects in presence of $\mathrm{O}$ and the diffusion of $\mathrm{O}$ in presence of substitutional solutes in the $\gamma$ phase of TiAl.

The interaction of oxygen with the vacancies and the anti-sites of the system will thus be investigated. To further complete this work, the effect of alloying elements will be studied. More precisely, the interactions between solutes and oxygen will be carried out using not only first- principles calculations but also thermodynamic models. One of the objectives is to estimate the influence of several substitutionnal solutes on the insertion energy of $\mathrm{O}$ in the alloy. From these calculations, the impact of these solutes on the $\mathrm{O}$ diffusivity will be evaluated.

The methodology (DFT and thermodynamic model) and preliminary results on the TiAl system are presented in section II. Section III discusses the concentration of intrinsic point defects in the TiAl system. The TiAl + $\mathrm{O}$ system is then addressed in Section IV, followed by a discussion on the substitutional elements in the $\mathrm{TiAl}$ system in Section V. Sections VI and VII give conclusions about the effect of solutes on the solubility and diffusivity of oxygen in the TiAl system.

\section{METHODS}

\section{A. DFT simulations}

DFT calculations were performed using the Vienna $a b$ initio simulation package (VASP) [27]. The selfconsistent Kohn-Sham equations were solved using the projector augmented wave (PAW) pseudo-potentials [28]. The Perdew-Burke-Ernzerhof (PBE [29]) exchange and correlation functional was used. As $\gamma$-TiAl is nonmagnetic, calculations were performed without magnetism. The plane-wave energy cut-off was set to $500 \mathrm{eV}$. Calculations were conducted on $3 \times 3 \times 3$ super-cells, i.e. 108 sites (54 Ti and $54 \mathrm{Al}$ ). $10 \times 10 \times 10$ Monkhorst-Pack meshes [30] were used to sample the first Brillouin zone. Ionic relaxations were introduced by using a conjugate-gradient algorithm, and supercell relaxations (volume and shape) were also made possible. Calculations were performed at zero pressure.

\section{B. IPDA thermodynamics}

The methodology of first-principles thermodynamics for ordered compounds is mainly based on the independent point defect approximation (IPDA) [31], an approach initiated in the 1990 s, because the increased accuracy of first-principles calculations made it significantly more interesting. The IPDA has the advantage of being versatile and much easier to implement - and perhaps just as reliable around stoichiometry - than more complex approaches such as the cluster expansion approach [32]. Much more than the latter, it can be extended to many cases of ordered alloys with complex structures, possibly containing additional elements [33-35], not necessarily including metallic bonding [36], and encompassing the various contributions to point defect free energies, e.g. point defect phonons [37]. Given the enormous number of existing ordered compounds, the IPDA thus provides a useful framework for analysis and interpretation, suitable for a wide field of potential applications. Noticeably, it allows to quickly characterize, in a rather system- 
atic way, an ordered compound for a given - ab initio or empirical - type of alloy energetics. It also provides an efficient tool to benchmark alloy energetics, sometimes allowing to highlight striking differences between energy models. In this context, the present work on TiAl offers a good opportunity to describe how the IPDA can be applied to multi-component systems containing several kinds of point defects.

The parameters required in the IPDA thermodynamic model are the so-called grand canonical free energies corresponding to the creation of each type of complex, simple or isolated point defect, which, at a temperature of $0 \mathrm{~K}$, correspond to grand canonical energies, $E_{g c}$. The ground-state point defect structure is thus obtained by minimizing the $T=0 \mathrm{~K}$ enthalpy of the system with respect to the point defect numbers at constant composition. For a given defect, $E_{g c}$ is expressed as:

$$
E_{g c}[\text { defect }]=E_{o}[\mathrm{TiAl}+\text { defect }]-E_{o}[\mathrm{TiAl}] .
$$

where $E_{o}$ are the DFT energies of the system with and without defect. However, the "true" thermodynamic quantity required to compute defect concentrations is the formation energy, $E_{f}[$ defect], of the defects. It is thus given by:

$$
E_{f}[\text { defect }]=E_{g c}-\Delta n_{\mathrm{Al}} \cdot \mu[\mathrm{Al}]-\Delta n_{\mathrm{Ti}} \cdot \mu[\mathrm{Ti}]
$$

where $\Delta n_{\mathrm{Al}}$ and $\Delta n_{\mathrm{Ti}}$ is the number of $\mathrm{Al}$ and Ti atoms added (negative) or subtracted (positive) to the system. The formation energies needed to compute the concentrations of point defects therefore depend on the chemical potentials of the elements present in the compound. In the case of binary $\mathrm{TiAl}$, the chemical potentials of $\mathrm{Al}$ and Ti atoms are linked by a constraint that is approximately given by:

$$
\mu[\mathrm{Al}]+\mu[\mathrm{Ti}]=E_{o}[\mathrm{TiAl}]
$$

In the approach used here, the concentration of $\mathrm{Ti}$ (and thus of $\mathrm{Al}$ ) is fixed, the value of the potential $\mu[\mathrm{Ti}]$ to satisfy this constraint is thus calculated. The constraint $\left(E_{o}[\mathrm{TiAl}]\right)$ corresponds to the energy of the perfect bulk. The defect concentration is thus expressed as:

$$
C_{\text {defect }}[T] \propto e^{-E_{f} / k_{B} T}
$$

where the proportionality depends on the degeneracy (multiplicity) of the defect.

\section{TiAl system}

The $L 1_{0} \gamma$-TiAl system belongs to space group $\mathrm{n}^{\circ}$ 123. It is an ordered compound with tetragonal structure where $\mathrm{Ti}$ and $\mathrm{Al}$ atoms occupy $1 a$ and $1 d$ sites, respectively. The face-centered tetragonal lattice was used in this work, but considered as pseudo face-centered cubic, because the lattice parameters are very similar: $\mathrm{a}_{o}=\mathrm{b}_{o}$ $=3.999 \AA$ and $\mathrm{c}_{o}=4.076 \AA$, see Fig. 1. This small dif-

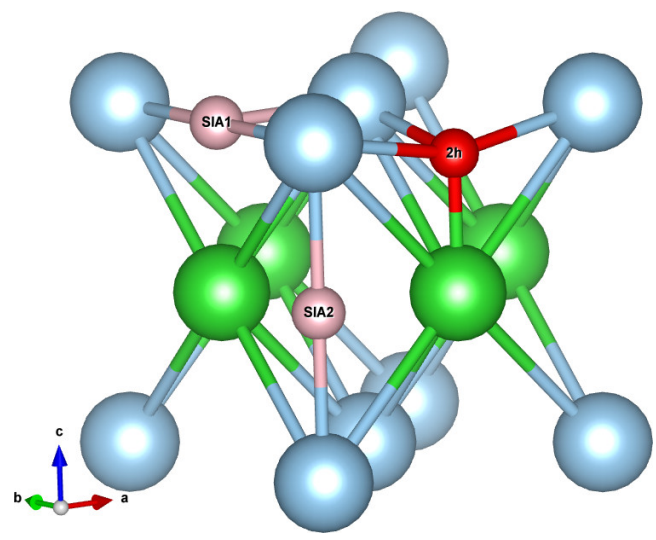

Figure 1. Schematic representation of the $\gamma$-TiAl system with one $\mathrm{O}$ in stable position (labeled $2 h$ ), and the two selfinterstitial positions (labeled SIA1 and SIA2). The green balls (resp. blue) are the $\mathrm{Al}$ atoms (resp. Ti).

ference induces a strong anisotropy in the structure and lifts the degeneracy of many equivalent sites as, for instance the octahedral and tetrahedral sites of the usual fcc structure. This is also why SIA1 and SIA2 sites are not equivalent, see Fig. 1. DFT simulations have already proved successful in accurately reproducing the groundstate properties of the $\gamma$-TiAl system, see for example Refs. [38, 39].

\section{INTRINSIC POINT DEFECTS IN THE TIAL SYSTEM}

\section{A. DFT results}

This first part reexamines the properties of the intrinsic point defects found in the $\mathrm{Ti}_{x} \mathrm{Al}_{1-x}$ system, around the stoichiometric composition, i.e. $x \simeq 0.5$. In the $L 1_{0}$ $\gamma$-TiAl system, there are three intrinsic point defects: the vacancies, the anti-sites and the self-interstitials. Regarding vacancies, there are two configurations: Ti vacancies (labeled $\mathrm{V}_{\mathrm{Ti}}$ ) or $\mathrm{Al}$ vacancies (Val). There are also two anti-sites, i.e. $\mathrm{Ti}$ (resp. $\mathrm{Al}$ ) atoms in $\mathrm{Al}$ (resp. Ti) sites, labeled $\mathrm{Ti}_{\mathrm{Al}}$ (resp. $\mathrm{Al}_{\mathrm{Ti}}$ ). As for self-interstitial defects, two configurations were considered, the added $\mathrm{Al} / \mathrm{Ti}$ atom thus occupies the SIA1 or SIA2 site (which correspond to octahedral and tetrahedral positions see Ref. [39]), as depicted in Fig. 1.

The grand canonical energies of the simple intrinsic point defects in $L 1_{0} \gamma$-TiAl are summarized in Table I.

As explained above, the formation energies, needed to compute the concentrations of point defects, depend on the chemical potentials of the elements present in the compound. It thus depends on the TiAl composition (Ti/Al ratio) and the temperature. The comparison of the stability of different defects is therefore tricky at this stage. 
Table I. Calculated values of grand canonical energies (in eV) of simple intrinsic point defects in $L 1_{0} \gamma$-TiAl.

\begin{tabular}{ccc|cc}
\hline \hline Species $\backslash$ site & $\mathrm{Ti}$ & $\mathrm{Al}$ & $\mathrm{SIA} 1$ & $\mathrm{SIA} 2$ \\
\hline vacancy & 9.71 & 6.47 & - & - \\
$\mathrm{Ti}$ & - & -3.28 & -2.01 & -3.61 \\
$\mathrm{Al}$ & 4.15 & - & +0.72 & +0.09 \\
\hline \hline
\end{tabular}

\section{B. Effect of temperature}

The approach described by Besson et al. [31, 33] was thus used here to compute concentrations and formation energies depending on temperature and $\mathrm{Ti} / \mathrm{Al}$ fraction. Calculations were performed at a fixed temperature, the fraction of $\mathrm{Ti} / \mathrm{Al}, x$, being left free to vary (in the present method, a chemical potential scan was carried out: for a value of $\mu[\mathrm{Ti}]$, there is one $\mu[\mathrm{Al}]$ value, eq. 3 , which corresponds to one $x$ concentration). A diagram indicating the stability of point defects around stoichiometry can then be established. Results are represented in Fig. 2.

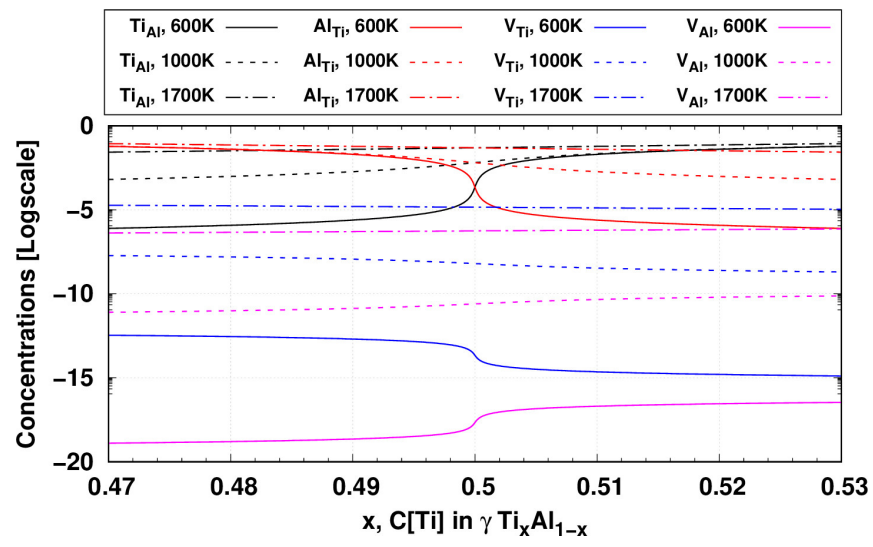

Figure 2. Point defect concentrations as a function of Ti content $x$ in the $\mathrm{Ti}_{x} \mathrm{Al}_{1-x}$ system, for three temperatures: 600, 1000 and $1700 \mathrm{~K}$.

As expected, the concentration of $\mathrm{Ti}$ vacancies (blue line in Fig. 2) is much higher than that of $\mathrm{Al}$ vacancies (magenta line), regardless of the titanium concentration present in the system, and the content of anti-sites is high on either side of stoichiometry. This result is in agreement with the common idea that in the sub-stoichiometry of $\mathrm{Ti}$ (resp. $\mathrm{Al}$ ), for example, $\mathrm{Al}$ (resp. Ti) atoms replace Ti atoms (resp. Al), on the sub-lattice sites. Regarding self-interstitial species, they were included in the IPDA model. However, their concentrations were all found to be low: lower than $10^{-20}$ at $1000 \mathrm{~K}$ and about $10^{-12}$ at $2000 \mathrm{~K}$. Their formation energies are in the range of $[4.3-6.5] \mathrm{eV}$ (see Supplemental material, section 1). They will thus be considered as negligible in the rest of the study.

The formation energies of the different defects obtained at different temperatures (300, 600, 1000 and 1700K) as a function of the titanium content in the system were also plotted, see Fig. 3. The formation energies of both types

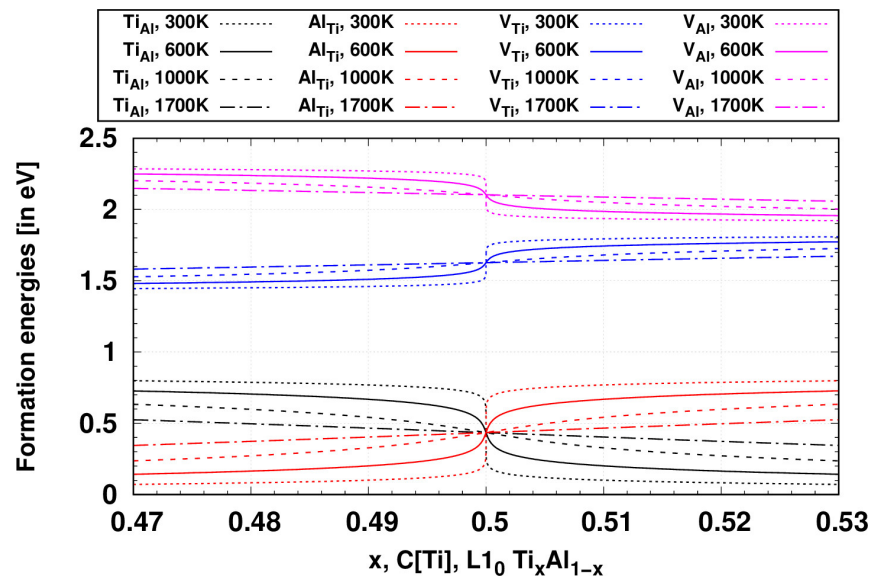

Figure 3. Formation energies of point defects in the $\mathrm{Ti}_{x} \mathrm{Al}_{1-x}$ system as a function of the Ti content for four temperatures: $300,600,1000$ and $1700 \mathrm{~K}$.

of vacancies are in the range of $[1.5-2.3] \mathrm{eV}$ depending on the Ti concentration, while the formation energy of antisites is almost equal to zero (in the range of $[0.1-0.7]$ $\mathrm{eV}$ ) when deviating from stoichiometry.

These results can now be compared to those found in the literature. They are in agreement with the results of Woodward [38], Herzig [40], Mishin [41], Hao [42] and Bakulin [43]. There still are discrepancies depending on the calculation method (EAM or DFT) and the approximation method (LDA or GGA functionals), as noticed by Bakulin [43]. Hao [42] obtained high DFT Al vacancy formation energies of about $2.98 \mathrm{eV}$, while Woodward $[38,44]$ found DFT values in better agreement with ours, about $2.0 \mathrm{eV}$. In the case of $\mathrm{V}_{\mathrm{Ti}}$, these aforementioned studies produced rather consistent values, in the range of $[1.2-1.8] \mathrm{eV}$ depending on the composition, see Ref. from Woodward et al. [38]. Nevertheless, the results gathered in Table II can be successfully compared with the results of Bakulin [43] (they also used the VASP code with the PBE functional, but calculations were performed on smaller supercells): the agreement for the grand canonical energies between the two works is excellent. The concentration of point defects and thus analysis are thus the same between both works. Remarkably, the value obtained in our study for $E_{f}\left[V_{T i}\right]$, about $1.69 \mathrm{eV}$ at stoichiometry, is in excellent agreement with the experimental measurements obtained by positron lifetime spectroscopy, about $1.4 \mathrm{eV}$ for the vacancy formation energy in the $\mathrm{Ti}_{52} \mathrm{Al}_{48}$ system $[45,46]$. For the $\mathrm{Al}$ vacancy formation energy there are no experimental values available, probably due to its high value. To conclude, the present results are considered accurate enough, and will be used hereinafter. 


\section{TIAL-O SYSTEM}

\section{A. DFT results}

As reported in previous works [24-26], in the TiAl system, O atoms prefer to occupy $2 h$ sites among many possible interstitial positions, see Fig. 1. O atoms are thus located (along the c axis of the tetragonal structure) above an $\mathrm{Al}$ atom at an interstitial position, but not at the octahedral position. These earlier studies indicated [24-26] that $\mathrm{O}$ has a strong affinity with Ti atoms, which explains for instance its high solubility in Ti systems. In these works, it was also shown that other interstitial positions have higher energies than the $2 h$ positions. To further enhance the model, a second insertion site was taken into account: the $2 e$ site, identical to the SIA2 configuration, see Fig. 1. It has a higher energy of about $0.88 \mathrm{eV}$ above that of the $2 h$ site. $2 h$ and $2 e$ sites are therefore used as interstitial $\mathrm{O}$ positions, while other interstitial sites are neglected. These two sites were then prioritized in the construction of the complex clusters.

In this context, an ab initio-based IPDA thermodynamic study is carried out in order to study oxygen insertion in $\gamma$-TiAl. Here, it is considered that $\mathrm{O}$ atoms can interact with (and without) intrinsic point defects and can form complex oxygen clusters. In addition to the two interstitial positions, many types of oxygen clusters are thus included in the model: vacancy-oxygen clusters (labeled $\left.\mathrm{V}_{\mathrm{Al}} \mathrm{O}_{n}, \mathrm{~V}_{\mathrm{Ti}} \mathrm{O}_{n}\right)$, anti-site-oxygen clusters $\left(\mathrm{Al}_{\mathrm{Ti}} \mathrm{O}_{n}\right.$, and $\mathrm{Ti}_{\mathrm{Al}} \mathrm{O}_{n}$ ) and oxygen aggregates around a "normal" $\mathrm{Ti}$ or $\mathrm{Al}$ atom (i.e. $\mathrm{Ti}_{\mathrm{Ti}} \mathrm{O}_{n}, \mathrm{Al}_{\mathrm{Al}} \mathrm{O}_{n}$ resp.). DFT simulations are performed for all these cases, with different $n$ values.

First, regarding the complexes involving a single $\mathrm{O}$ atom ( $\mathrm{n}=1$, first row of Table II), various configurations around a vacancy are displayed in Fig. 4. For similar $(n=1)$ clusters around anti-sites, only two configurations for $\mathrm{O}$ atoms are considered: when the $\mathrm{O}$ atom is either in the $2 h$ site or in the $2 e$ site (cases 3 and 4 on the left, cases 4 and 3 on the right). For larger O-vacancy clusters $\mathrm{V}_{Y} \mathrm{O}_{n}$ with $n \geq 2$, several configurations built from the two favorable $\mathrm{O}$ sites $2 h$ and $2 e$ are considered up to $\mathrm{n}=6$. For similar $\mathrm{O}$ complexes $(n \geq 2$, anti-sites and $\mathrm{O}$ aggregates), the investigation is limited to smaller values, i.e. $n \leq 3$.

To analyze these results, another energy is introduced in addition to grand canonical energies: the oxygen segregation energy, $E_{\text {seg }}\left[V_{Y} O_{n}\right]$. It corresponds to the energy needed/gained to segregate an $\mathrm{O}$ atom onto a $\mathrm{V}_{Y} \mathrm{O}_{n-1}$ complex defect (the most stable configuration $n-1$ ):

$$
\begin{aligned}
& E_{s e g}\left[V_{Y} O_{n}\right]=E_{o}\left[\mathrm{TiAl}+V_{Y} O_{n}\right]+E_{o}[\mathrm{TiAl}] \\
& \quad-E_{o}\left[\mathrm{TiAl}+O_{i n t}\right]-E_{o}\left[\mathrm{TiAl}+V_{Y} O_{n-1}\right] .
\end{aligned}
$$

$E_{o}\left[\mathrm{TiAl}+V_{Y} O_{n}\right]$ is the DFT energy of the system with a $\mathrm{V}_{Y} \mathrm{O}_{n}$ cluster $(\mathrm{Y}=\mathrm{Al}$ or $\mathrm{Ti}), E_{o}[\mathrm{TiAl}]$ is the energy of the perfect system, $E_{o}\left[\mathrm{TiAl}+O_{\text {int }}\right]$ the energy of an $\mathrm{O}$ atom in its interstitial position and $E_{o}\left[\mathrm{TiAl}+V_{Y} O_{n-1}\right]$

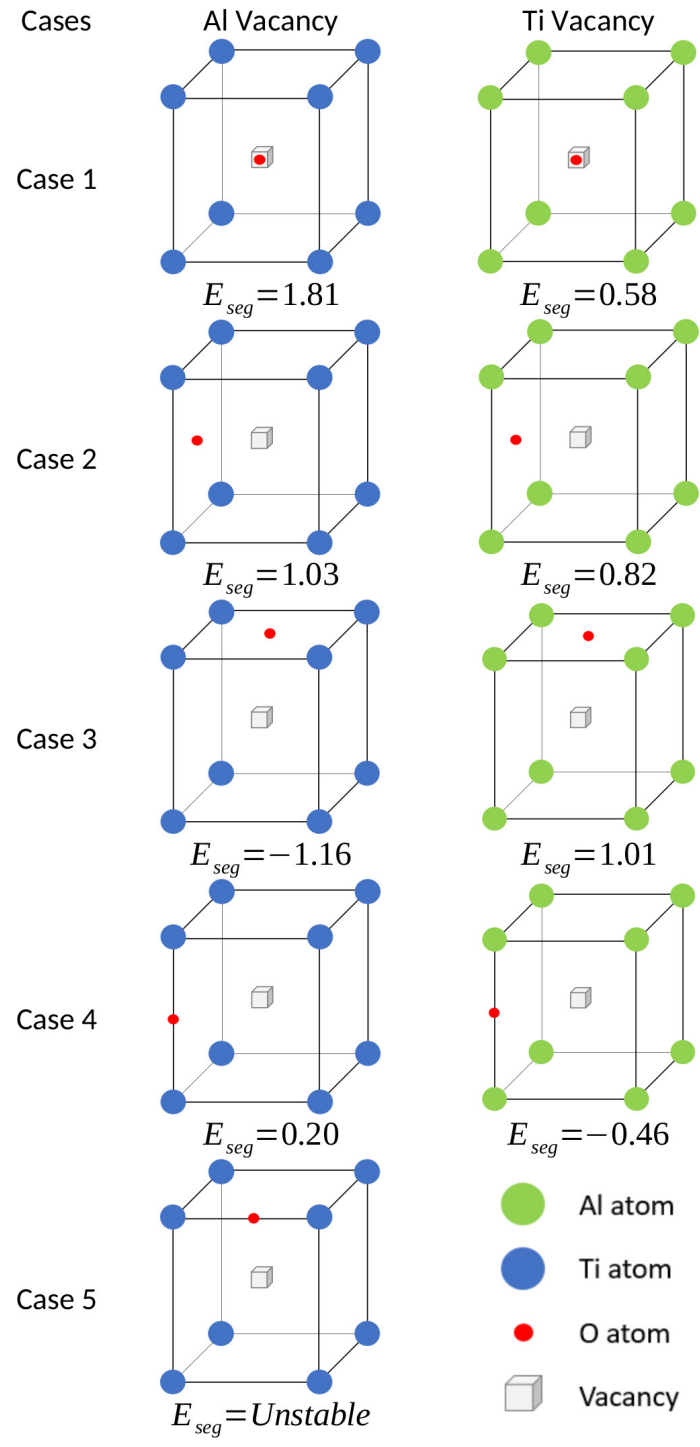

Figure 4. Schematic representation of the different configurations of complex defects composed of one vacancy and one oxygen, $\mathrm{V}_{Y} \mathrm{O}_{1}$, where $\mathrm{Y}=\mathrm{Al}$ (left) or $\mathrm{Ti}$ (right). The energy indicated under each configuration corresponds to the oxygen segregation energy as defined in the text, which in this case $(n=1)$ is identical to the oxygen-vacancy binding energy. A body-centered tetragonal (bct) representation was chosen to represent the $L 1_{0}$ TiAl structure.

the DFT energy of the most stable $\mathrm{V}_{Y} \mathrm{O}_{n-1}$ cluster. A negative value of $E_{\text {seg }}\left[V_{Y}+O_{n}\right]$ therefore means that an $\mathrm{O}$ atom prefers to segregate on a $\mathrm{V}_{Y} \mathrm{O}_{n-1}$ cluster rather than staying alone in its interstitial position. Results on the most stable configurations are summarized in Table II, and full results are depicted in Fig. 5.

Before discussing "true" complexes (i.e. O around intrinsic point defects), a preliminary case is also displayed in Fig. 5 (cases 1 on Fig. 4), which corresponds to an isolated $\mathrm{O}$ atom in substitution, the $\mathrm{O}$ atom being located either in a $\mathrm{Ti}$ or in a $\mathrm{Al}$ sub-lattice site. This configuration is not energetically favorable $\left(E_{s e g}>0\right)$. Overall, 
Table II. Calculated values of grand canonical energies (in eV) for oxygen clusters in $L 1_{0} \gamma$-TiAl. In parentheses, the segregation energies, $E_{\text {seg }}$ (in $\mathrm{eV}$ ), are also given.

\begin{tabular}{|c|c|c|c|c|c|c|}
\hline \multicolumn{2}{|c|}{$\mathrm{O}$ in $2 h$} & \multicolumn{2}{|l|}{-8.37} & \multicolumn{2}{|c|}{$\mathrm{O}$ in $2 e$} & \multirow{2}{*}{$\begin{array}{c}-7.49 \\
\mathrm{Al}_{\mathrm{Al}}\end{array}$} \\
\hline Cluster $\backslash \mathrm{X}$ & $\mathrm{V}_{\mathrm{Ti}}$ & $\mathrm{V}_{\mathrm{Al}}$ & $\mathrm{Al}_{\mathrm{Ti}}$ & $\mathrm{Ti}_{\mathrm{Al}}$ & $\mathrm{Ti}_{\mathrm{Ti}}$ & \\
\hline $\mathrm{XO}_{1}$ & $0.82(-0.46)$ & $-3.11(-1.16)$ & $-3.54(0.74)$ & $-12.68(-0.98)$ & $-8.37(2 h)$ & $-8.37(2 h)$ \\
\hline $\mathrm{XO}_{2}$ & $8.11(-0.51)$ & $12.66(-1.29)$ & - & $-21.85(-0.75)$ & $-16.69(0.16)$ & $-16.82(0.03)$ \\
\hline $\mathrm{XO}_{3}$ & $16.87(-0.34)$ & $20.94(0.14)$ & - & $-29.22(1.05)$ & - & - \\
\hline $\mathrm{XO}_{4}$ & $25.80(-0.51)$ & $29.26(0.11)$ & - & - & - & - \\
\hline $\mathrm{XO}_{5}$ & $32.24(+1.99)$ & $37.49(0.19)$ & - & - & - & - \\
\hline $\mathrm{XO}_{6}$ & $41.46(-0.81)$ & $44.36(1.55)$ & - & - & - & - \\
\hline
\end{tabular}

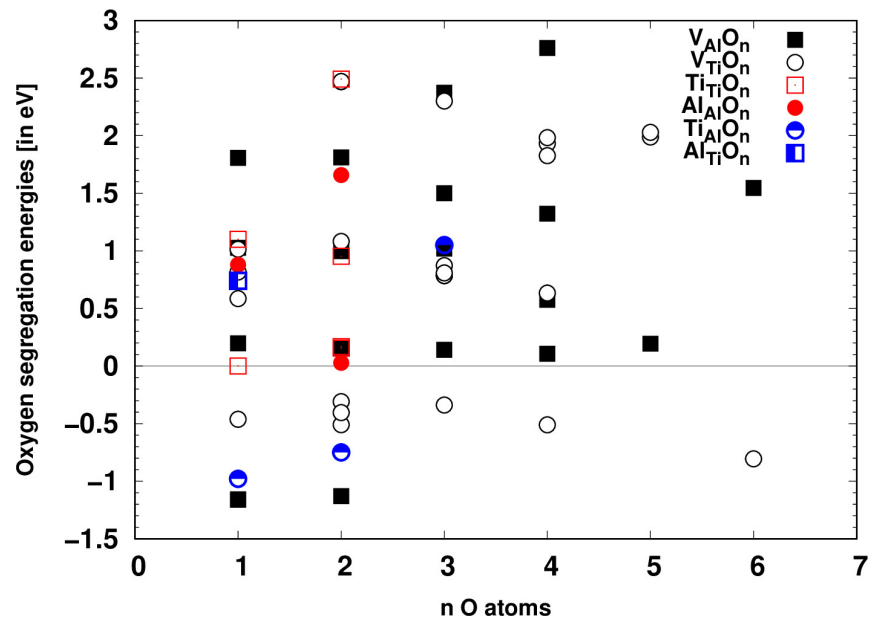

Figure 5. Segregation energies for oxygen clusters located around vacancies $\left(\mathrm{V}_{\mathrm{Ti}} \mathrm{O}_{n}, \mathrm{~V}_{\mathrm{Al}} \mathrm{O}_{n}\right)$, anti-sites $\left(\mathrm{Al}_{\mathrm{Ti}} \mathrm{O}_{n}\right.$, $\left.\mathrm{Ti}_{\mathrm{Al}} \mathrm{O}_{n}\right)$ or "normal" atoms $\left(\mathrm{Ti}_{\mathrm{Ti}} \mathrm{O}_{n}, \mathrm{Al}_{\mathrm{Al}} \mathrm{O}_{n}\right)$.

Table II clearly shows that $\mathrm{O}$ atoms strongly segregate on vacancies and anti-sites, especially on $\mathrm{Al}$ vacancies or $\mathrm{Ti}_{\mathrm{Al}}$ anti-sites which display significant segregation energies, $\simeq-1 \mathrm{eV}$. Remarkably, this enhanced cluster stability holds only for a small number of $\mathrm{O}$ atoms, typically $n \leq 2-3$. For the most stable configuration of $\mathrm{V}_{\mathrm{Al}} \mathrm{O}_{1}$ (case 3, in Fig. 4), the oxygen is in the vicinity of $\mathrm{Ti}$ atoms: the most stable configuration corresponds to two equivalent positions where oxygen atoms occupy the $2 h$ sites, above and below the intrinsic defect. This result is consistent with the previous analysis of oxygen insertion in the defect-free TiAl system. By increasing $n$ around an $\mathrm{Al}$ vacancy, the most stable $\mathrm{V}_{\mathrm{Al}} \mathrm{O}_{2}$ configuration is reached when the two $\mathrm{O}$ atoms are on either side of the $\mathrm{Al}$ vacancy position, in the two $2 h$ positions. The other configurations where $\mathrm{O}$ is not in $2 h$ are always less energetically favorable. When $n$ is greater than 2 , as there are two $\mathrm{O}$ atoms in the $2 h$ positions, the others have to be located in the less stable $2 e$ sites. This explains the positive segregation energies found then for $\mathrm{V}_{\mathrm{Al}} \mathrm{O}_{n}$.

Around a Ti vacancy, "case 4" is the most stable configuration for $\mathrm{V}_{\mathrm{Ti}} \mathrm{O}_{1}$, see Fig. 4. There are four equivalent possibilities for this case. In these configurations, all complex oxygen clusters composed of oxygen are therefore energetically favorable. Up to $n=4, V_{T i} O_{n}$ are thus energetically favorable, the most stable being those composed exclusively of these sites. However, as soon as a cluster is composed of one or more $\mathrm{O}$ atoms in another site is less stable than the others. This explains why positive segregation energies are obtained for clusters containing $n=5$ or more $\mathrm{O}$ atoms.

These results lead to the conclusion that $\mathrm{O}$ segregation around aluminum vacancies is favored but that only clusters of at most two oxygen atoms can form. On the other hand, around Ti vacancies, segregation energies are less strong but still negative, so that configurations are also favored and clusters including up to four $\mathrm{O}$ atoms can be formed. These results are valid at $0 \mathrm{~K}$, but in order to assess the competition and stability among configurations, thermal effects must now be taken into account.

Concerning $\mathrm{O}$ clusters around anti-site atoms, a few configurations were tested. A specific attention was paid to the cases that should be the most stable, i.e. the configurations where $\mathrm{O}$ atoms are placed in $2 h$ sites. As with O-vacancy clusters, O atoms prefer a Ti-rich environment, i.e. $\mathrm{Ti}_{\mathrm{Al}}$. The oxygen segregation energy on $\mathrm{Ti}_{\mathrm{Al}},-0.98 \mathrm{eV}$, is found to be close to that obtained for the segregation around an $\mathrm{Al}$ vacancy $(-1.16 \mathrm{eV})$. However, as seen in the previous section, the anti-site concentration, which depends on the $\mathrm{Ti} / \mathrm{Al}$ ratio, is much greater than the vacancy concentration. We can therefore anticipate on the following, by concluding that complex $\mathrm{Ti}_{\mathrm{Al}}+\mathrm{O}$ defects are likely to be the majore defects.

The last type of defects considered in the present study are those composed of oxygen only, either around a "normal" $\mathrm{Al}$ (labeled $\mathrm{Al}_{\mathrm{Al}} \mathrm{O}_{n}$ ) or $\mathrm{Ti}$ atom $\left(\mathrm{Ti}_{\mathrm{Ti}} \mathrm{O}_{n}\right)$. But results show that such $\mathrm{O}$ aggregates are not favored. Indeed, their segregation energy is always positive, see Fig. 5 .

\section{B. Effect of temperature}

From these energies, $\mathrm{O}$ defect concentrations can now be determined as a function of temperature, and as a function of the $\mathrm{Ti} / \mathrm{Al}$ fraction, $x$, in the $\mathrm{Ti}_{x} \mathrm{Al}_{1-x}$ system. Many configurations were inserted in the IPDA model: 

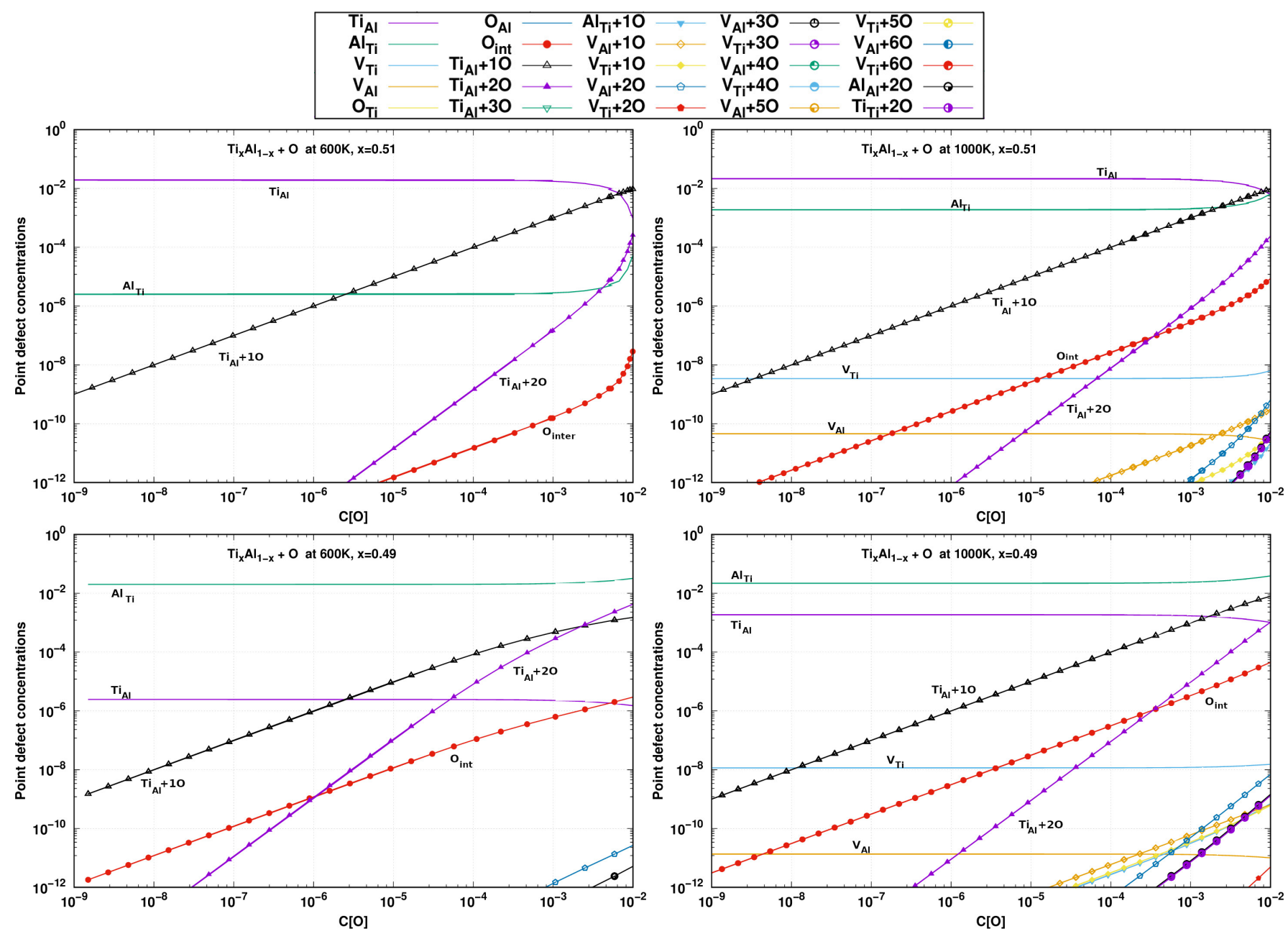

Figure 6. (color online) Concentration of clusters and point defects calculated at 600 and $1000 \mathrm{~K}$ as a function of oxygen concentration in the $\mathrm{Ti}_{x} \mathrm{Al}_{1-x}$ system, where $x=0.51$ (top) and 0.49 (bottom). Lines with symbols correspond to $\mathrm{O}$ clusters. A large number of symbols were represented in the legend, these are all defects (complex or not) used in the ADPI. Only a few have concentrations above $10^{-3} \mathrm{ppb}$. These are the ones discussed in the text.

both kinds of vacancies and anti-sites, two interstitial positions (the most stable and the second most stable, as explained above) and all complex defects described previously. For these thermodynamic calculations, two temperatures $(600$ and $1000 \mathrm{~K})$ and two initial binary compositions of $\mathrm{Ti}_{x} \mathrm{Al}_{1-x}, x=0.51$ and 0.49 , were considered (results for additional temperatures are provided in the Supplemental Material section). The plots were drawn as a function of the total oxygen concentration present in the system. Results are plotted in Figs. 6 for $x=0.51$ and 0.49 .

The results show that, at thermodynamic equilibrium, in all cases, $\mathrm{O}$ atoms are located in the vicinity of $\mathrm{Ti}$ anti-sites and in isolated interstitial positions. The situation depends somewhat on the TiAl ratio and on the temperature. For $x=0.51$, the main complex defect is $\mathrm{Ti}_{\mathrm{Al}} \mathrm{O}_{1}$. The main change in the concentrations concerns the second most stable complex, indeed, $\mathrm{O}$ may appear either in isolated form or as a $\mathrm{Ti}_{\mathrm{Al}} \mathrm{O}_{2}$ defect, de- pending on the temperature. For $x=0.49$ (and at the stoichiometry too), at low temperature, $\mathrm{Ti}_{\mathrm{Al}} \mathrm{O}_{2}$ defects are more stable, but when $\mathrm{T}$ increases, the fraction of $\mathrm{Ti}_{\mathrm{Al}} \mathrm{O}_{1}$ clusters increases to become the main ones. The $\mathrm{O}$ concentration in isolated interstitial positions remains negligible in comparison to other complex defects. Some profiles become steeper for $C[O]$, between $10^{-3}$ and $10^{-2}$ $\mathrm{O}$ at.ppm, but these oxygen concentrations are not encountered in the $\mathrm{TiAl}$ system, where the concentration is limited at about 230 at.ppm.

The concentration of $\mathrm{Ti}_{\mathrm{Al}} \mathrm{O}_{2}$ is generally lower than that of $\mathrm{Ti}_{\mathrm{Al}} \mathrm{O}_{1}$, even though the segregation energies are always negative, i.e. -0.98 and $-0.75 \mathrm{eV}$, see Table II. This is due to the fact that the true thermodynamic quantity is the energy of formation, and that it depends on the chemical potential of $\mathrm{O}$. There is a somewhat subtle effect of $\mathrm{T}$ and $x$ which does not appear in the mere values of $E_{\text {seg. }}$. For instance, at high temperature, the concentration of anti-site defects is high $\left(>10^{-3}\right)$, whichever the 
value of $x$, this favors the formation of clusters containing oxygen. When the concentration of $\mathrm{Ti}_{\mathrm{Al}}$ anti-sites is low, $\mathrm{Ti}_{\mathrm{Al}} \mathrm{O}_{2}$ becomes the main complex cluster, this can be observed at low temperature. These results will have an important effect on the diffusivity of oxygen and the $\mathrm{Ti}_{\mathrm{Al}}$ defects should be considered as a trap for oxygen atoms: the oxygen atoms will diffuse from complex cluster to complex cluster, consequently, the diffusivity of $\mathrm{O}$ will be slowed down significantly. Moreover, results show that the oxygen-vacancy affinity, suggested by the results presented in Table II, is not sufficient to induce an increase in the vacancy concentration.

However, in practical, solute elements are added to TiAl alloys for various purposes: increasing mechanical strength, improving oxidation resistance, increasing formability, and so on (a review of these effects can be found in Ref. [47]). Though in some cases the added elements tend to segregate, or promote phase transformation, they can also remain, at least partly, in solid solution in the $\gamma$ phase. After having outlined accurately the behavior of oxygen in TiAl, it thus seems reasonable to wonder about the effect produced by the addition of extra metallic elements in this ternary Al-O-Ti system. Could they change the intrinsic defect concentrations, form complex defects with oxygen, and thus modify oxygen insertion and eventually oxygen diffusivity?

\section{TIAL +X SYSTEM}

\section{A. DFT results}

This section investigates the addition of substitutional solutes in the TiAl system. This encompasses at the same time the solutes already present in TiAl alloys used industrially (such as $\mathrm{Nb}, \mathrm{Cr}, \mathrm{W}$ or $\mathrm{Mo}$ ) and many others. Several authors have already investigated solute species in the TiAl system, such as Woodward [38] and Jiang [48]. These works will be used for comparison purposes. Similar to vacancies and anti-sites, there are two possible sites for inserting alloying elements. They can be found either in place of a $\mathrm{Ti}$ atom or in place of an $\mathrm{Al}$ atom. Both positions were tested for 27 alloying elements to determine which is the preferential site for each of them. The grand canonical energy, $\mathrm{E}_{g c}\left[X_{Y}\right]$, of solute $\mathrm{X}$ on a $\mathrm{Y}$ site, where $\mathrm{Y}=\mathrm{Ti}$ or $\mathrm{Al}$ is defined as:

$$
E_{g c}\left[X_{Y}\right]=E_{o}\left[\mathrm{TiAl}+X_{Y}\right]-E_{o}[\mathrm{TiAl}]
$$

where $E_{o}[A]$ is the DFT energy of the system $A$, with or without a complex defect. Results are summarized in Table III.

Grand canonical energies cannot be used directly to predict where solutes are preferentially located in the compound. The true quantity governing point defects amounts is the formation energy, $E_{f}\left[X_{Y}\right]$,

$$
E_{f}\left[X_{Y}\right]=E_{g c}\left[X_{Y}\right]-\mu[X]+\mu[Y]
$$

It depends on the chemical potential of $\mathrm{X}, \mu[X]$, and on that of $\mathrm{Ti}$ and $\mathrm{Al}$ in the $\mathrm{TiAl}$ system, i.e. $\mu[Y](\mathrm{Y}=\mathrm{Ti}$, $\mathrm{Al})$. By defining $\Delta E_{f}[X]=E_{f}\left[X_{T i}\right]-E_{f}\left[X_{A l}\right]$, the site preference of $X$ is thus given by the positive or negative sign of $\Delta E_{f}[X]$, which is unknown here. In order to circumvent this problem, it may be useful to compare the magnitude of another quantity, $E_{b}\left[X_{Y}\right]$, given by:

$$
E_{b}\left[X_{Y}\right]=E_{o}\left[\mathrm{TiAl}+X_{Y}\right]-E_{o}\left[\mathrm{TiAl}+V_{Y}\right]
$$

This determines the energy difference between the system with an $\mathrm{X}$ atom inside the $\mathrm{Y}$ sub-lattice and the $\mathrm{Y}$ vacancy. Similarly, the energy difference can be defined as $\Delta E_{b}[X]=E_{b}\left[X_{T i}\right]-E_{b}\left[X_{A l}\right]$, which can also be expressed as a function of $\Delta E_{f}[V]$ and $\Delta E_{f}[X]$ :

$$
\Delta E_{b}[X]=\Delta E_{f}[X]-\Delta E_{f}[V]
$$

where $\Delta E_{f}[V]$ is the relative stability of vacancies expressed by:

$$
\Delta E_{f}[V]=E_{f}\left[V_{T i}\right]-E_{f}\left[V_{A l}\right]
$$

The sign of $\Delta E_{f}[X]$, which governs $\mathrm{X}$ behavior in TiAl, is thus given by the sign of $\Delta E_{f}[V]+\Delta E_{b}[X]$. If $\Delta E_{b}[X]$ is greater (resp. lower) than $-\Delta E_{f}[V]$, then an $\mathrm{X}$ solute should be located preferentially in $\mathrm{Al}$ (resp. Ti) sites, otherwise it should be equally distributed in both sublattices. In section III, the vacancy formation energies, calculated as a function of $x$ and temperature, were found in the range of $[1.5 ; 1.8] \mathrm{eV}$ for $\mathrm{V}_{\mathrm{Ti}}$ and $[1.9 ; 2.3] \mathrm{eV}$ for $\mathrm{V}_{\mathrm{Al}}$, hence $-\Delta E_{f}[V]$ is in the range of $[0.4 ; 0.8] \mathrm{eV}$ depending on the $\mathrm{Ti} / \mathrm{Al}$ ratio in the alloy. To analyze the site preference of $\mathrm{X}$ atoms from equation (7), $\Delta E_{b}[X]$ should therefore be compared to the values 0.4 (Ti-rich TiAl) and $0.8 \mathrm{eV}$ (Al-rich TiAl). This analysis was ap-

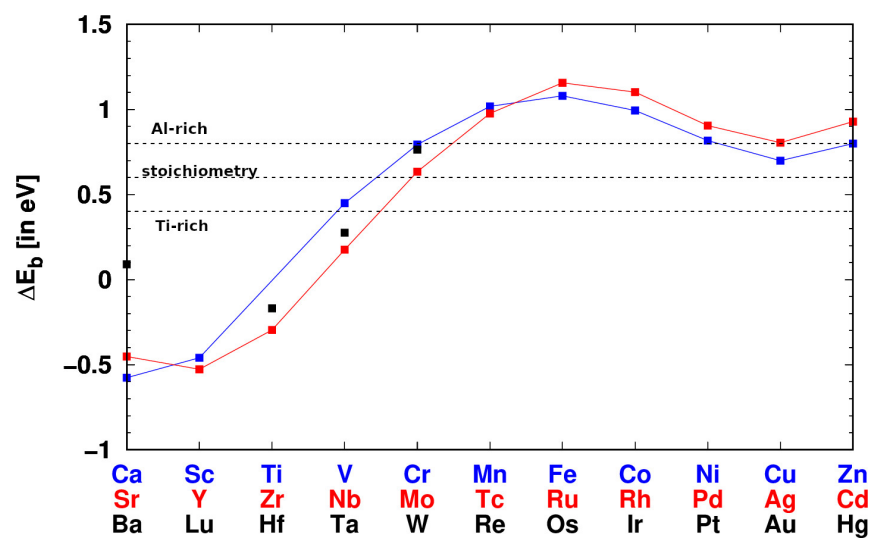

Figure 7. $E_{b}\left[X_{T i}\right]-E_{b}\left[X_{A l}\right]=\Delta E_{b}[X]$ as a function of the $\mathrm{X}$ element. The dashed lines, about 0.4 and $0.8 \mathrm{eV}$, correspond to the limit cases between $\mathrm{Al}$ and $\mathrm{Ti}$ sites occupation, in Tirich and Al-rich TiAl respectively.

plied to all solutes listed in Table III, and $\Delta E_{b}$ is displayed in Fig. 7 as a function of X. This shows a clear trend for site preference of solutes: elements on the left side of the periodic table prefer to be located onto $\mathrm{Ti}$ sites, while the other elements should replace Al. The cases of Si and Ge follow this tendency as well. 
Table III. Grand canonical energy, $\mathrm{E}_{g c}\left[X_{Y}\right]$ in $\mathrm{eV}$, of solute $\mathrm{X}$ on $\mathrm{Y}$ site $(\mathrm{Al}$ or $\mathrm{Ti}) . E_{b}\left[X_{Y}\right]$ energies are also given. For each solute, the preferential site deduced from equation (7) is marked with an asterisk.

\begin{tabular}{|c|c|c|c|c|c|c|c|c|c|c|c|c|c|}
\hline & $\mathrm{Ca}$ & $\mathrm{Sc}$ & $\mathrm{Ti}$ & $\mathrm{V}$ & $\mathrm{Cr}$ & $\mathrm{Mn}$ & $\mathrm{Fe}$ & $\mathrm{Co}$ & $\mathrm{Ni}$ & $\mathrm{Cu}$ & $\mathrm{Zn}$ & $\mathrm{Al}$ & $\mathrm{Vac}$ \\
\hline $\mathrm{Al} E_{g c}$ & 5.11 & -1.00 & -3.28 & -4.38 & -4.74 & -4.54 & -3.84 & -2.83 & -1.58 & 0.71 & 3.06 & - & 6.47 \\
\hline$E_{b}$ & -1.37 & -7.47 & -2.32 & $-10.85^{*}$ & $-11.21^{*}$ & $-11.01^{*}$ & $-10.31^{*}$ & $-9.30^{*}$ & $-8.05^{*}$ & $-5.77^{*}$ & $-3.41^{*}$ & - & \\
\hline $\mathrm{Ti} E_{g c}$ & 7.76 & 1.87 & - & -0.69 & -0.71 & -0.28 & 0.48 & 1.40 & 2.48 & 4.63 & 7.09 & 4.15 & 9.71 \\
\hline \multirow[t]{2}{*}{$E_{b}$} & $-1.94^{*}$ & $-7.83^{*}$ & - & -10.40 & -10.41 & -9.99 & -9.23 & -8.31 & -7.23 & -5.07 & -2.6 & -12.98 & \\
\hline & $\mathrm{Sr}$ & $\mathrm{Y}$ & $\mathrm{Zr}$ & $\mathrm{Nb}$ & Mo & Tc & $\mathrm{Ru}$ & $\mathrm{Rh}$ & $\mathrm{Pd}$ & $\mathrm{Ag}$ & $\mathrm{Cd}$ & $\mathrm{Si}$ & \\
\hline $\mathrm{Al} E_{g c}$ & 6.55 & -0.28 & -3.51 & -5.62 & -6.58 & -6.59 & -5.77 & -4.24 & -1.93 & 1.89 & 3.98 & -2.07 & \\
\hline$E_{b}$ & 0.08 & -6.76 & -9.99 & -12.09 & $-13.05^{*}$ & $-13.06^{*}$ & $-12.24^{*}$ & $-10.71^{*}$ & $-8.40 *$ & $-4.58^{*}$ & $-2.49 *$ & $-8.54^{*}$ & \\
\hline $\operatorname{Ti} E_{g c}$ & 9.33 & 2.42 & -0.57 & -2.21 & -2.71 & -2.38 & -1.37 & 0.10 & 2.21 & 5.93 & 8.14 & 2.31 & \\
\hline \multirow[t]{2}{*}{$E_{b}$} & $-0.38^{*}$ & $-7.28^{*}$ & $-10.28^{*}$ & $-11.91^{*}$ & -12.42 & -12.09 & -11.08 & -9.61 & -7.49 & -3.78 & -1.56 & -7.40 & \\
\hline & $\mathrm{Ba}$ & $\mathrm{Lu}$ & $\mathrm{Hf}$ & $\mathrm{Ta}$ & W & $\mathrm{Re}$ & Os & Ir & $\mathrm{Pt}$ & $\mathrm{Au}$ & $\mathrm{Hg}$ & $\mathrm{Ge}$ & \\
\hline $\mathrm{Al} E_{g c}$ & 6.90 & - & -4.89 & -7.14 & -8.38 & & & & & & & -1.04 & \\
\hline$E_{b}$ & 0.52 & - & -11.37 & $-13.61^{*}$ & $-14.85^{*}$ & & & & & & & $-7.51^{*}$ & \\
\hline Ti $E_{g c}$ & 10.23 & - & -1.83 & -3.63 & -4.38 & & & & & & & 3.33 & \\
\hline$E_{b}$ & $0.42^{*}$ & - & $-11.54^{*}$ & $-13.33^{*}$ & -14.08 & & & & & & & -6.37 & \\
\hline
\end{tabular}

\section{B. Thermodynamic model}

The previous analysis provides a good insight into the behavior of substitutional solutes in TiAl. It can now be refined by using the temperature-dependent IPDA model. The focus was put on three elements, see Fig. 7: $\mathrm{Nb}, \mathrm{Cr}$ and $\mathrm{Mo}$ (additional cases are presented in the Supplemental Material, section 3). They are representative of substitutional solutes in TiAl (Table III), as Nb and $\mathrm{Cr}$ should respectively prefer to be located onto $\mathrm{Ti}$ and $\mathrm{Al}$ sites, while Mo should occupy equivalently both sub-lattices (Fig. 7). Considering three temperatures $(600,1000$ and $1700 \mathrm{~K})$ and two $x \mathrm{Ti} / \mathrm{Al}$ ratios $(\mathrm{x}=0.49$ and 0.51 ), results for $\mathrm{Nb}, \mathrm{Cr}$ and $\mathrm{Mo}$ atoms are displayed in Fig. 8-10, respectively.

As indicated previously $\mathrm{Nb}$ atoms substitute preferentially on $\mathrm{Ti}$ sites. Looking at Fig. 8 for $x=0.51$, titanium concentration is higher than that of aluminum (hence $\mathrm{Ti}_{\mathrm{Al}}$ intrinsic defects), but when $\mathrm{Nb}$ concentration increases, the number of $\mathrm{Ti}$ sites filled with $\mathrm{Nb}$ atoms also increases. In order to compensate and preserve the $\mathrm{Ti} / \mathrm{Al}$ fraction, the $\mathrm{Al}$ sub-lattice is then increasingly filled with $\mathrm{Ti}$ atoms, therefore the $\mathrm{Ti}_{\mathrm{Al}}$ concentration increases and the amount of $\mathrm{Al}_{\mathrm{Ti}}$ anti-sites decreases. When $x=0.49$, at low $\mathrm{Nb}$ concentration, the main of intrinsic defects are $\mathrm{Al}_{\mathrm{Ti}}$, because there are more $\mathrm{Al}$ atoms than $\mathrm{Ti}$ atoms. Moreover, $\mathrm{Nb}$ atoms substitute for the intrinsic minority element, i.e. they form $\mathrm{Nb}_{\mathrm{Ti}}$ defects. When the insertion rate of $\mathrm{Nb}$ approaches the deviation from stoichiometry $(\mathrm{C}[\mathrm{Nb}] \simeq \mathrm{x})$, the conservation of the mole number entails an abrupt addition-induced reorganization of the defect structure. Namely (i) addition elements are increasingly substituted on the Al sub-lattice, and simultaneously (ii) there is a shift in majority intrinsic anti-sites in favor of $\mathrm{Ti}_{\mathrm{Al}}$. As the temperature increases, the occupancy rates of the two sites are closer and the effect on the intrin- sic defects is weaker. There is therefore a competition between $\mathrm{Al}$ and $\mathrm{Nb}$ atoms when it comes to fill the $\mathrm{Ti}$ sub-lattice.

Experimental findings [49] and previous theoretical works, Jiang [48] and Woodward [38], showed that Nb atoms are located in $\mathrm{Ti}$ sub-lattices. This is in agreement with the results found in the present study.

In the case of chromium (Fig. 9), a similar two-fold behavior (depending on the value of $x$ ) is obtained: the defect profiles for $\mathrm{Cr}$ can be roughly deduced from those found for $\mathrm{Nb}$ by reversing the roles of $\mathrm{Ti}$ and $\mathrm{Al}$. As expected from Fig. 7, Cr is found to preferentially occupy Al sites whichever the temperature and the Ti/Al ratio. This confirms that the analysis of Fig. 7 conveniently allows to predict where substitutional solutes should be located in the TiAl system. For $\mathrm{Cr}$, the same as for $\mathrm{Nb}$ but in a Ti-rich compound, the thermodynamic analysis also confirms that drastic changes in the defect structure are expected when the amount of addition elements and the off-stoichiometry become roughly equal $(\mathrm{C}[\mathrm{Cr}] \simeq$ $\mathrm{x})$. Surprisingly, when comparing our theoretical results with earlier experimental observations, the concordance for $\mathrm{Cr}$ is not as good as for Nb. Indeed, Hao [49] found experimentally that $\mathrm{Cr}$ atoms should prefer the Ti sublattice. Further investigations on this interesting issue might help to determine if the disagreement is due to the IPDA modeling (possible role of Cr clusters), to deficiencies in the DFT energetics in presence of $\mathrm{Cr}$, or to uncertainties in the experimental conclusions.

The last case presented focuses on Mo solutes, see Fig. 10. Due to its rather particular status (it is the only solute located right in the middle of the threshold domain indicated in Fig. 7), this element is expected to have the most intermediate behavior among all solutes considered in this work considering site occupancy in TiAl. Indeed, the thermodynamic behavior of Mo is similar to that of 

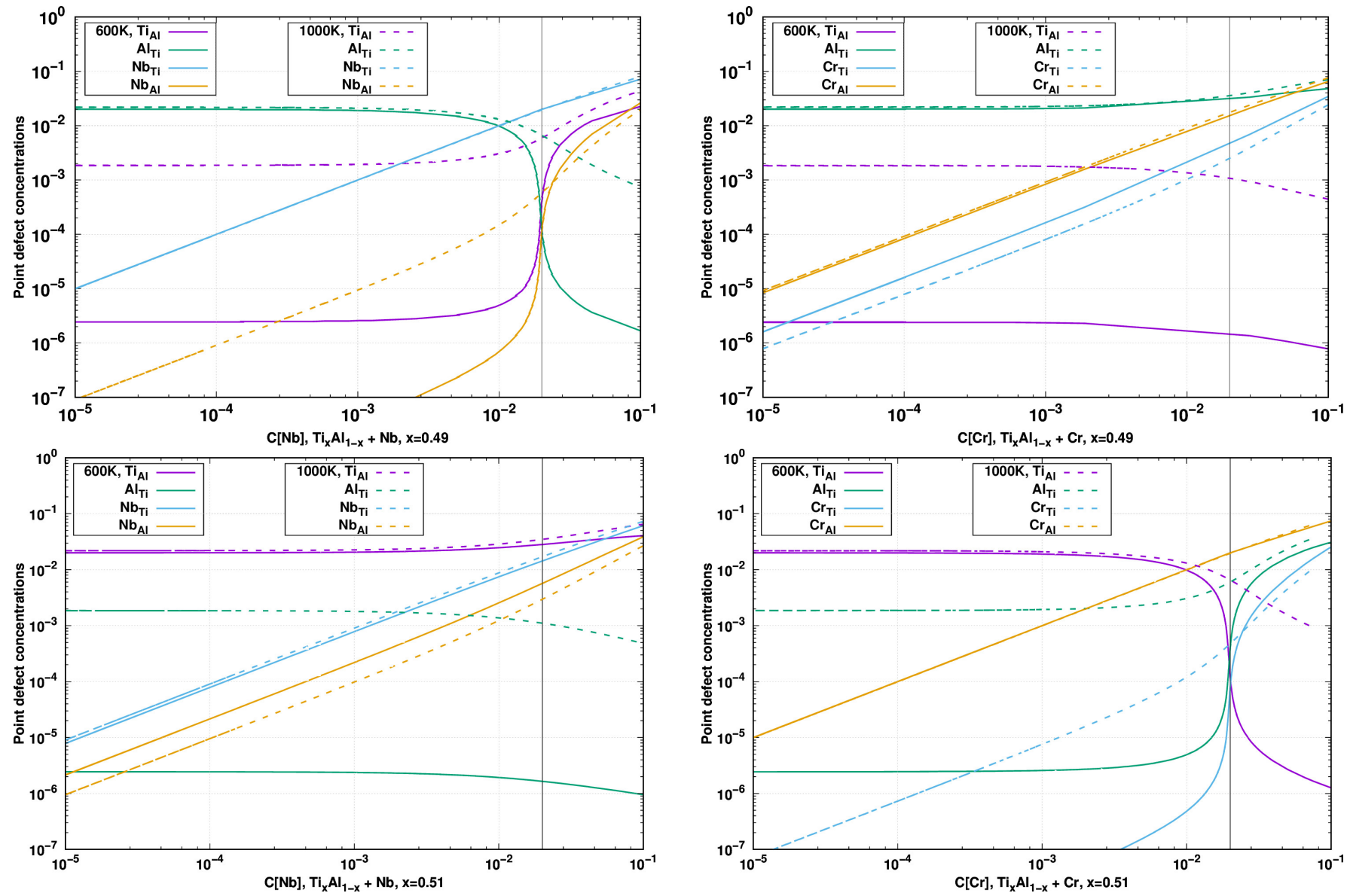

Figure 8. Concentration of point defects calculated at 600 , 1000 and $1700 \mathrm{~K}$ as a function of $\mathrm{Nb}$ concentration in the $\mathrm{Ti}_{x} \mathrm{Al}_{1-x}$ system, where $x=0.49$ (up) and $x=0.51$ (down). The vertical black line corresponds to a concentration of $2 \%$.

Figure 9. Concentration of point defects calculated at 600, 1000 and $1700 \mathrm{~K}$ as a function of $\mathrm{Cr}$ concentration in the $\mathrm{Ti}_{x} \mathrm{Al}_{1-x}$ system, where $x=0.49$ (up) and $x=0.51$ (down). The vertical black line corresponds to a concentration of $2 \%$.

chromium, but the defect diagram in the Al-rich compound $(\mathrm{x}=0.49)$ shows that molybdenum occupies both sub-lattices at the same time. At high concentration, Mo atoms occupy both sub-lattices, as seen with the ratio displayed in Fig. 11. Moreover, the behavior of Mo also differs slightly from its $\mathrm{Cr}$ counterpart for $\mathrm{x}=0.51$, since the defect reversal starts at lower amounts of solute $(\mathrm{C}[\mathrm{Mo}]<\mathrm{x})$, which favor an earlier competition between $\mathrm{Mo}_{\mathrm{Ti}}$ and $\mathrm{Al}_{\mathrm{Ti}}$. Thermodynamic results for the other solutes listed above are given in the Supplemental Material.

In conclusion, the simple method based on the results of fig. 7 can be used to determine the position of substitution solutes in the TiAl lattice.

\section{TIAL $+\mathrm{X}+\mathrm{O}$ SYSTEM}

\section{A. DFT results}

The interactions between oxygen and alloying elements can now be investigated. It is therefore important because it provides insight into the effect of a solute on the

insertion of $\mathrm{O}$ in the TiAl system. The results obtained previously on $\mathrm{O}$ clusters around intrinsic defects allow to reduce the number of configurations that ought to be taken into account: three (resp. two) configurations for the insertion of an $\mathrm{O}$ atom in the vicinity of a solute $\mathrm{X}$, when $\mathrm{X}$ is on a $\mathrm{Ti}$ (resp. $\mathrm{Al}$ ) sub-lattice, $\mathrm{X}_{\mathrm{Ti}}\left(\right.$ resp. $\mathrm{X}_{\mathrm{Al}}$ ). Such configurations are those in which the oxygen atom was found to have the lowest energy in the presence or absence of vacancies or anti-sites (cases 3 and 4 of Fig. 4). To further complete this, when $\mathrm{X}$ is on the $\mathrm{Al}$ sub-lattice, one additional configuration is also considered which corresponds to the case of oxygen-solute-clusters composed of two $\mathrm{O}$ atoms and one $\mathrm{X}$. The final selected configurations, namely a total of six O-X candidate clusters, are depicted on Fig. 12.

In order to characterize the behavior of $\mathrm{O}$ in the vicinity of $\mathrm{X}$, it is helpful to use, as previously, the segregation (or binding) energy of an $\mathrm{O}$ atom on $\mathrm{X}_{Y} \mathrm{O}_{n-1}$, 

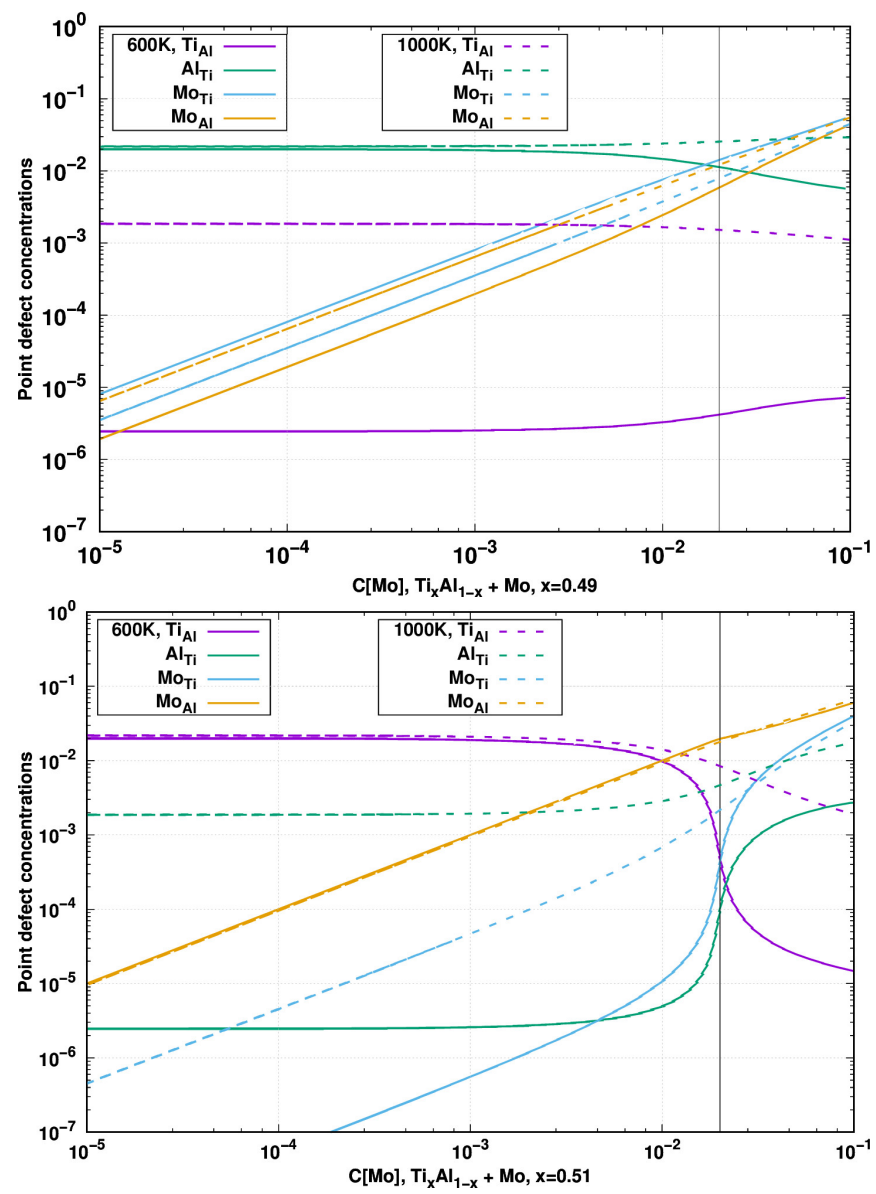

Figure 10. Concentration of point defects calculated at 600, 1000 and $1700 \mathrm{~K}$ as a function of Mo concentration in the $\mathrm{Ti}_{x} \mathrm{Al}_{1-x}$ system, where $x=0.49$ (up) and $x=0.51$ (down). The vertical black line corresponds to a concentration of $2 \%$.

$E_{\text {seg }}^{n}[O, X]$, defined by:

$$
\begin{aligned}
& E_{\text {seg }}^{n}[O, X]=E_{o}\left[\mathrm{TiAl}+X_{Y}+O_{n}\right]+E_{o}[\mathrm{TiAl}] \\
& -E_{o}\left[\mathrm{TiAl}+X_{Y}+O_{n-1}\right]-E_{o}[\mathrm{TiAl}+O]
\end{aligned}
$$

$E_{o}\left[\mathrm{TiAl}+X_{Y}+O_{n}\right]$ is the DFT supercell energy of the $\mathrm{X}_{Y} \mathrm{O}_{n}$ complex defect considered, $E_{o}[\mathrm{TiAl}]$ is the energy of the ideal with no defects supercell, and $E_{o}\left[\mathrm{TiAl}+X_{Y}+\right.$ $\left.O_{n-1}\right]$ and $E_{o}[\mathrm{TiAl}+O]$ are respectively the supercell energies for $\mathrm{X}$ on a $\mathrm{Y}$ site $(\mathrm{Y}=\mathrm{Ti}$ or $\mathrm{Al})$ surrounded by $n$ $\mathrm{O}$ atoms and for $\mathrm{O}$ in its most stable configuration, i.e. 2h. As stated previously, if $\mathrm{E}_{\text {seg }}$ is negative, the $\mathrm{X}-\mathrm{O}_{n-1}$ cluster attracts an extra $\mathrm{O}$ atom, whereas if positive, the cluster repels the oxygen atom.

The segregation energies for one $\mathrm{O}$ atom (i.e. for $n=1$ in equation 11) around $X_{Y}$ are depicted in Fig. 13 and Fig. 14. It can be seen that the most stable case is always configuration 1 for both sub-lattices. Furthermore, onto the Ti sub-lattice, almost all $\mathrm{X}$ elements repel $\mathrm{O}$ atoms, except Ca, Y, Sc and Sr. On the contrary, when the alloying element is located on the $\mathrm{Al}$ sub-lattice, the segregation is strong. The further to the left of the periodic

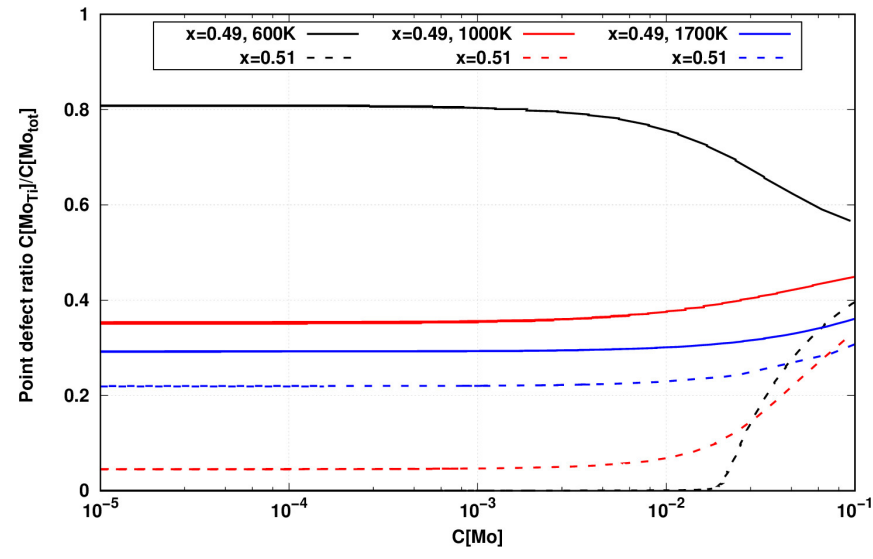

Figure 11. $C\left[\mathrm{Mo}_{T i}\right] / C\left[\mathrm{Mot}_{t o t}\right]$ ratio calculated at 600,1000 and $1700 \mathrm{~K}$ as a function of Mo concentration in the $\mathrm{Ti}_{x} \mathrm{Al}_{1-x}$ system, where $x=0.49$ and $x=0.51$.

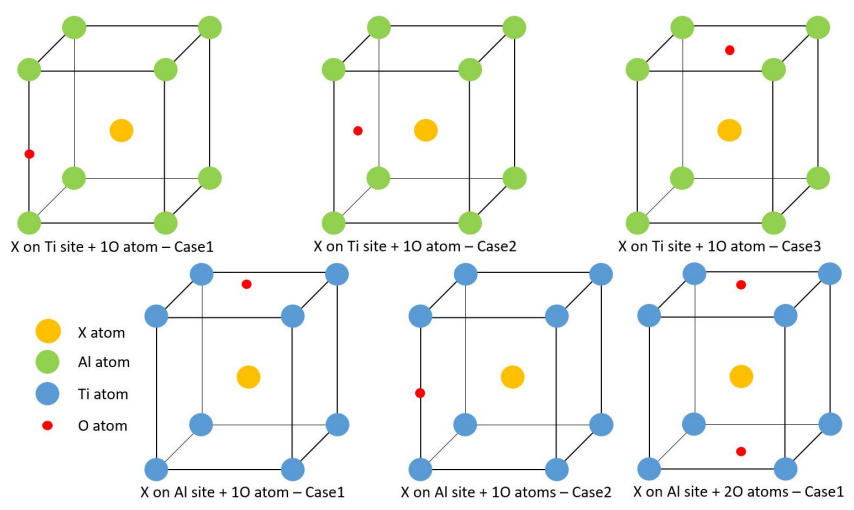

Figure 12. Schematic representation of solute-oxygen configurations in $\mathrm{TiAl}$ considered in the present work.

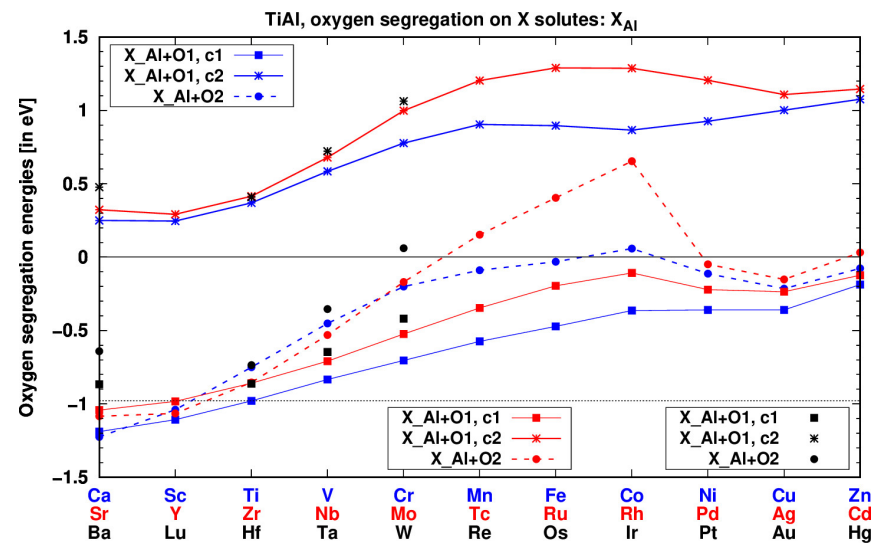

Figure 13. Oxygen segregation on $\mathrm{X}$ solutes: $X_{A l}+\mathrm{O}_{1,2}$. The dotted line refers to the segregation energy, $-0.98 \mathrm{eV}$, of $\mathrm{O}$ on the $\mathrm{Ti}_{\mathrm{Al}}$ anti-site, see text.

table, the more attractive the element for O. Moreover, it was shown (previous section) that $\mathrm{O}$ segregation on $\mathrm{Ti}_{\mathrm{Al}}$ anti-sites is strong, and it can thus be compared to that of solutes. From Table I, the "reference" segregation 


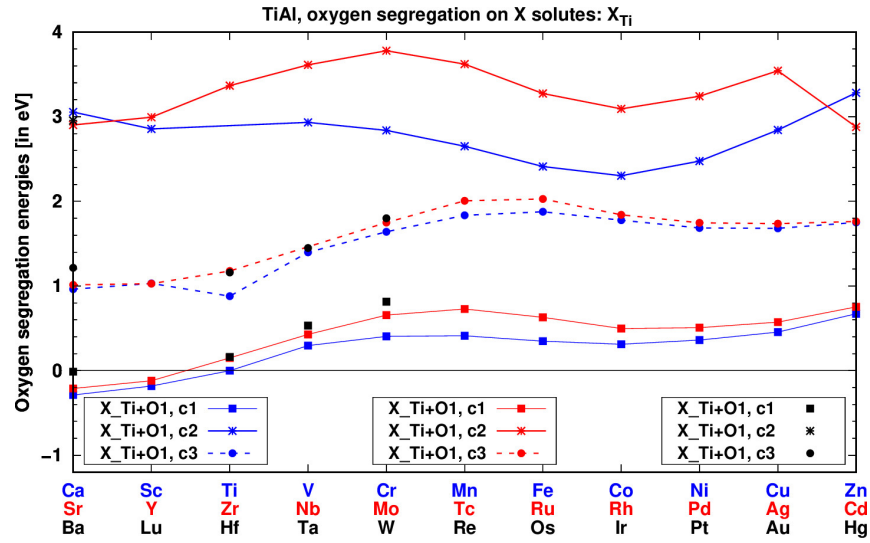

Figure 14. Oxygen segregation on $\mathrm{X}$ solutes: $X_{T i}+\mathrm{O}_{1,2}$.

energy around $\mathrm{Ti}_{\mathrm{Al}}$ is $-0.98 \mathrm{eV}$ for the first $\mathrm{O}$ atom, and $-0.75 \mathrm{eV}$ for the second one. Fig. 13 shows that Ti is one of the most attractive elements for oxygen, and only few elements on the left side of the periodic table segregate oxygen more strongly than the $\mathrm{Ti}_{\mathrm{Al}}$ anti-site.

Oxygen seems to be attracted near $\mathrm{X}_{\mathrm{Al}}$ only in the configuration 1 . There are two equivalent sites to build this complex defect. We therefore studied the segregation of a second atom on the other site, see Fig. 13. The segregation energy is found slightly lower than for one atom, but remains negative overall as for the first oxygen atom. These conclusions based on segregation energies are representative of the situation at $0 \mathrm{~K}$. It is therefore interesting to investigate the influence of temperature, in order to check which alloying elements are indeed more efficient oxygen traps than titanium antisites. All solute-oxygen configurations from Fig. 12 were included in the model, even though some are expected to exhibit negligible concentrations.

\section{B. Thermodynamic results}

Considering all configurations, the evolution of the concentrations of complex defects in the TiAl-X-O system can be upgraded by including small X-O clusters. Fig. 15 and 16 respectively display the results for $\mathrm{Nb}$ and $\mathrm{Cr}$, since these two solutes are representative enough to draw general conclusions. Furthermore, a solute content equals to 2 at.\% was considered, for two temperatures, i.e. 600 and $1000 \mathrm{~K}$. This value of $2 \%$ is representative of the solute contents typically found in many materials [47]. For such high amounts, the solute effect on $\mathrm{O}$ insertion is strongly exacerbated, as illustrated below.

Two trends appear. The first one concerns the case where the $\mathrm{X}$ solute (here $\mathrm{Nb}$, Fig. 15) is preferentially located on the $\mathrm{Ti}$ sub-lattices. The $\mathrm{O}$ atoms then remain located near $\mathrm{Ti}_{\mathrm{Al}}$ anti-sites, despite a favorable $\mathrm{O}-\mathrm{Nb}$ interaction. The concentration of $\mathrm{Nb}_{\mathrm{Ti}} \mathrm{O}$ clusters is significantly smaller than that of $\mathrm{Nb}_{\mathrm{Al}} \mathrm{O}$. This is valid whatever the temperature, and the $\mathrm{Ti} / \mathrm{Al}$ ratio. The second trend concerns the case where the $\mathrm{X}$ (here Cr, Fig. 16) solute is located on $\mathrm{Al}$ sites. Results thus show that at low temperature, $\mathrm{O}$ atoms prefer to form aggregates with $\mathrm{Cr}$ atoms whatever the $\mathrm{Ti} / \mathrm{Al}$ fraction. At higher temperature, when the $\mathrm{Ti} / \mathrm{Al}$ fraction is greater than 0.5 , the $\mathrm{O}$ atom prefers to form $\mathrm{Ti}_{\mathrm{Al}} \mathrm{O}$ clusters, otherwise, they form both kinds of defects, i.e. $\mathrm{Ti}_{\mathrm{Al}} \mathrm{O}$ and $\mathrm{Cr}_{\mathrm{Al}} \mathrm{O}$. Due to the high $\mathrm{X}$ content ( 2 at. \%) chosen here, the insertion of oxygen thus preferentially occurs through the formation of $\mathrm{O}$ clusters around $\mathrm{Cr}_{\mathrm{Al}}$ or $\mathrm{Ti}_{\mathrm{Al}}$. Since the sub-lattices occupied by $\mathrm{Nb}$ and $\mathrm{Cr}$ solutes are different, this leads to small differences, i.e. oxygen atoms are located in the vicinity of $\mathrm{Cr}_{\mathrm{Al}}$. This effect is less pronounced when the $\mathrm{X}$ concentration decreases.

These results show that the insertion of $\mathrm{O}$ atoms in $\gamma$ $\mathrm{TiAl}$ is more complex than expected. At thermodynamic equilibrium, the impact of solutes and anti-sites is strong. Oxygen is not only on isolated interstitial form but rather forms small complex defects. Solutes and anti-sites can thus be considered as oxygen traps, which are likely to have an influence on the diffusion of oxygen. The next and last section focuses on evaluating the impact of the presence of these traps on the diffusivity of $\mathrm{O}$ in $\gamma$-TiAl.

\section{EFFECT ON OXYGEN DIFFUSIVITY}

The effect of intrinsic point defects and solutes on oxygen diffusivity will be discussed hereinafter. Without traps (as solute substitutional or anti-sites interacting with the $\mathrm{O}$ atoms diffusing in interstitial sites), the diffusion coefficients of oxygen according to the crystallographic directions were studied and expressed in literature $[24-26]$. In these works, the atomic process of oxygen diffusivity were investigated. It was then assumed that $\mathrm{O}$ atoms diffuse from interstitial sites to interstitial sites, between $\mathrm{Ti}$ and $\mathrm{Al}$ atoms. By adding the present results to the argumentation, alloying elements and ( $\mathrm{Ti}$, $\mathrm{Al}$ ) anti-sites can be viewed as oxygen traps. Here, as a first approximation, the mobility of complex defects is supposed to be negligible compared to the interstitial diffusivity. The $\mathrm{O}$ atom can be trapped by either the solute atom or the anti-site (which is assumed not to move) or by both. Oriani [50] thus proposed an analytical expression for taking into account the oxygen trapping. Kirchheim [51] then generalized this model to multi-traps in the context of random walks. The effective diffusivity can be expressed as:

$$
D_{\mathrm{eff}}=\frac{D_{\text {ideal }}}{1+\sum_{i \in\{\text { traps }\}} C_{i} \exp \left[-\frac{E_{\text {seg }}^{i}}{k_{B} T}\right]}
$$

where $D_{\text {ideal }}$ is the ideal diffusion coefficient of oxygen in interstitial positions $[24,26]$, and $C_{i}$ and $E_{\text {seg }}^{i}$ the trap content in the system and the segregation energy of an $\mathrm{O}$ atom at trap of kind $i$, respectively. It was used successfully in the case of hydrogen diffusivity in the Ni system $[52]$. 

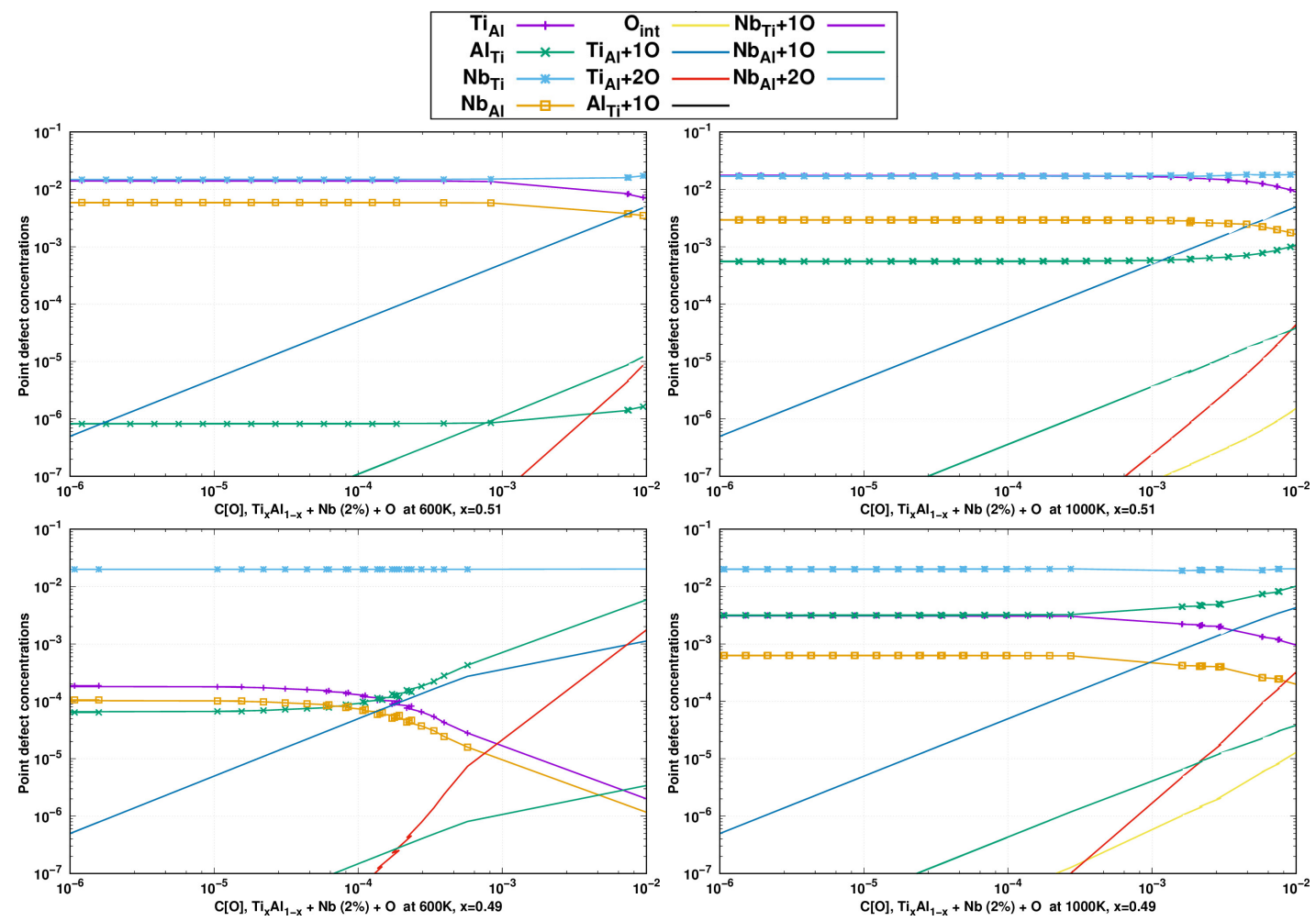

Figure 15. Concentration of complex defect and point defects calculated at 600 (left) and 1000K (right) as a function of oxygen concentration in the $\mathrm{Ti}_{x} \mathrm{Al}_{1-x}+\mathrm{Nb} 2$ at.\%, $\mathrm{x}=0.51$ (top) and 0.49 (bottom). The defects listed in the legends are not the only ones included in the thermodynamic model, but when the concentrations are too low to be observed there are not included in the graph. $\mathrm{Nb}_{\mathrm{Ti}} \mathrm{O}_{1}, \mathrm{Nb}_{\mathrm{Ti}} \mathrm{O}_{2}$ and $\mathrm{Al}_{\mathrm{Ti}} \mathrm{O}_{1}$ concentrations are lower than $10^{-8}$.

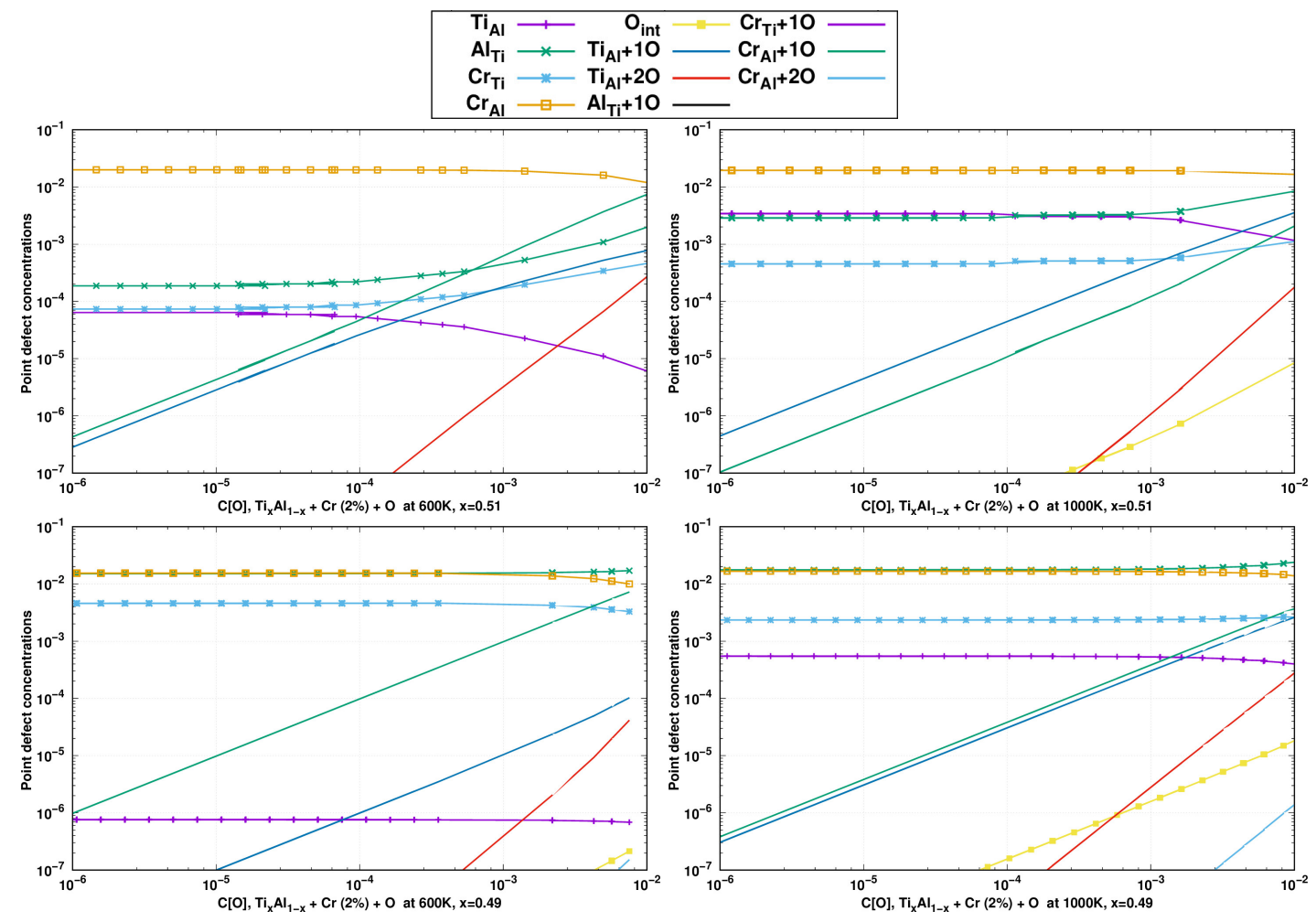

Figure 16. Concentration of complex defect and point defects calculated at 600 (left) and 1000K (right) as a function of oxygen concentration in the $\mathrm{Ti}_{x} \mathrm{Al}_{1-x}+\mathrm{Cr} 2 \mathrm{at} . \%, \mathrm{x}=0.51$ (top) and 0.49 (bottom). 
The ratio $R=D_{\text {eff }} / D_{\text {ideal }}$ was used to analyze the effect of Ti anti-sites and substitutional solutes on oxygen diffusivity. Fig. 17 shows the plot of this ratio as a function of temperature for different values of $E_{\text {seg }}$ [trap], different solute concentrations $(0,0.5,1$ and $2 \%)$ and different $\mathrm{Ti}_{x} \mathrm{Al}_{1-x}$ concentrations. In Eq. 12, two types of traps were considered: $\mathrm{Ti}_{\mathrm{Al}}$ and $\mathrm{X}_{\mathrm{Al}}$. The solute concentration was kept as parameter, while the Ti anti-site concentrations were extracted from the thermodynamic model and assumed unchanged by the solute and oxygen, in first approximation.

The main result provided by Fig. 17 is that oxygen diffusion coefficient is slower in presence of solutes and antisites than in the ideal case. This effect seems to be significant: the calculations predict a decrease of the diffusion coefficient by several orders of magnitude, in comparison with the evaluations in the simple case of interstitial diffusion without interactions with solutes $[24,26]$. Moreover, the specific effect of the added element depends strongly on the $\mathrm{Ti} / \mathrm{Al}$ ratio of the alloying $\mathrm{Ti}_{x} \mathrm{Al}_{1-x}$ system. Thus, for the value of $x=0.49$ and 0.50 , the concentration of $\mathrm{Ti}_{\mathrm{Al}}$ anti-sites is low, the decrease in oxygen diffusivity in $R$ is then limited to $1 \%$. When an $\mathrm{X}$ element with $\mathrm{O}$ segregation energy greater than $-0.5 \mathrm{eV}$ is added, even at 2 at.\%, no additional oxygen slowdown is observed. To identify the influence of the solute, Fig. 13 and 14 can be used: the elements on the right of $\mathrm{Fe}$ in the periodic table should not modify the diffusivity of O. In the second case, i.e. when $x=0.51$, a strong slowdown of oxygen diffusion, due to segregation on titanium anti-sites, is observed. Ti anti-sites have such a high trapping effect that addition elements can not entail any additional contribution. It is also interesting to note that $\mathrm{Al}_{\mathrm{Ti}}$ defects (namely including a third type of trap in eq. 12) do not modify the oxygen diffusivity, as their segregation energy is always positive or slightly negative $(>-0.2 \mathrm{eV})$.

These results tend to indicate that, with respect to ideal interstitial diffusion, the diffusion coefficients in TiAl alloys containing either solute substitutionnal and/or Ti anti-sites, is significantly diminished. This probably accounts for the fact that the experimental diffusion coefficient of $\mathrm{O}$ found by Zalar $\left(10^{-14} \mathrm{~m}^{2} / \mathrm{s}\right.$ at $700^{\circ} \mathrm{C}$ ) [22] is lower by three orders of magnitude than the theoretical values found for interstitial diffusion without interactions $\left(10^{-11} \mathrm{~m}^{2} / \mathrm{s}\right.$ at $\left.700^{\circ} \mathrm{C}\right)[24,26]$. However, the diffusion coefficients of $\mathrm{O}$ in presence of solutes remain to be experimentally determined and compared to the theoretical predictions of this study.

\section{CONCLUSION}

This paper contains an exhaustive chemical study and a thorough discussion on the solubility and diffusivity of oxygen in the $L 1_{0} \gamma \mathrm{TiAl}$ system. On one hand it presents atomic scale results regarding the formation of complex defects and, on the other hand, a thermodynamic anal-
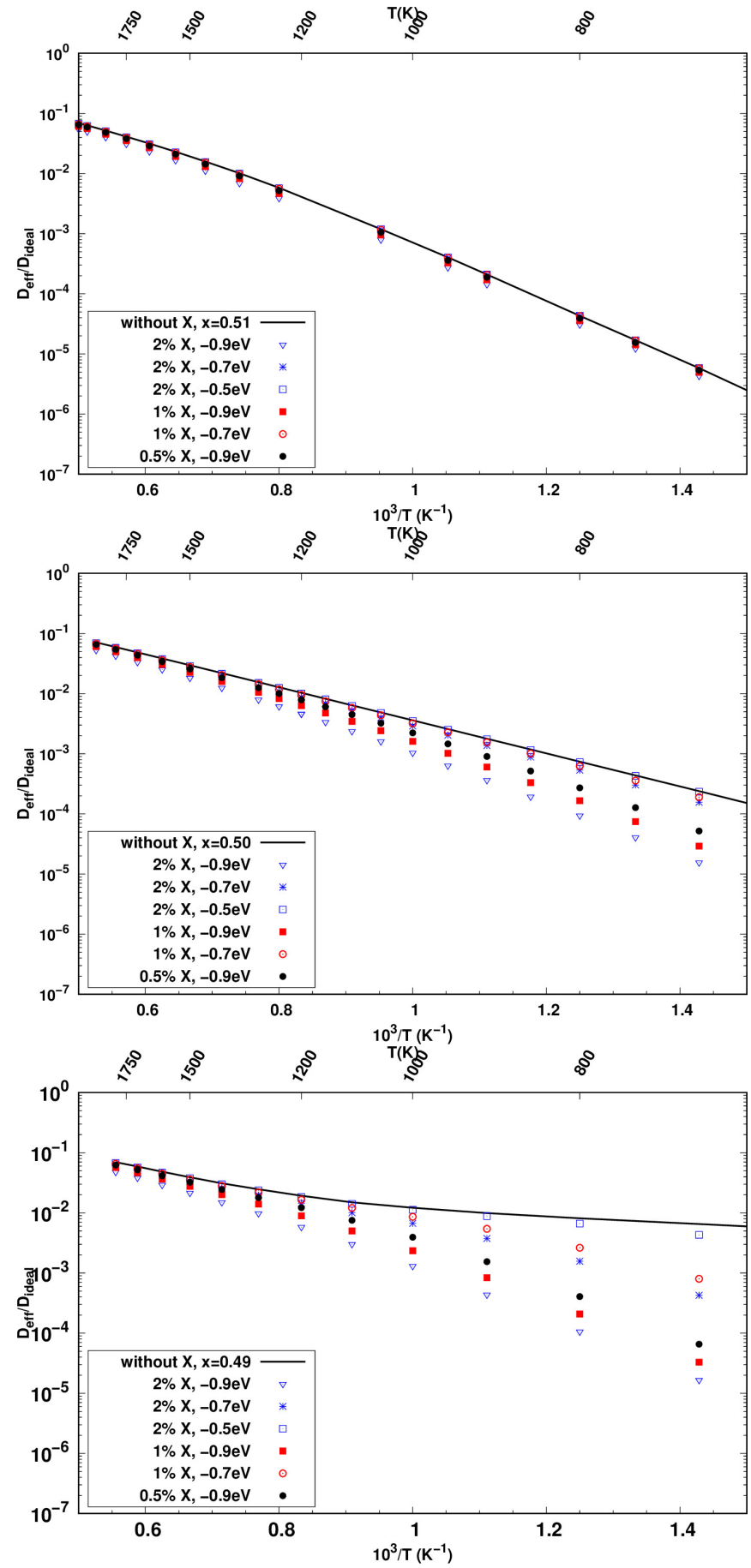

Figure 17. $\quad R=D_{\text {eff }} / D_{\text {ideal }}$, the effective/ideal diffusion coefficient ratio as a function of $\mathrm{O}$ segregation energies around X solutes. $R=D_{\text {eff }} / D_{\text {ideal }}$ is calculated for different values of $E_{\text {seg }}$ [trap] (in eV), different solute concentrations (0, 0.5, 1 and 2 at. \%) and different $\mathrm{Ti}_{x} \mathrm{Al}_{1-x}$ concentrations, i.e. $x=$ 0.51 (top), 0.50 (middle) and 0.49 (bottom).

ysis of the concentration of these defects as a function of temperature and $\mathrm{TiAl}$ ratio (with or without addition elements). At the atomic scale, results clearly show that anti-sites, especially $\mathrm{Ti}_{\mathrm{Al}}$, strongly attract oxygen. 
Oxygen segregation is favored by the fact that the local environment is rich in titanium atoms. Moreover, when an $\mathrm{X}$ addition element mainly replaces aluminum, the Al-depleted chemical environment favors the interaction between $\mathrm{X}$ and $\mathrm{O}$.

At thermodynamic equilibrium, the situation is more contrasted than expected. Indeed, different behaviors are observed depending on temperature and chemical composition. Intrinsic defects and alloying elements strongly modify the insertion of $\mathrm{O}$ in the TiAl system. The presence of anti-sites is thus crucial; the oxygen atoms are not located in the ideal interstitial sites (as it was assumed at first) but in complex defects. In most cases, the main complex defect composed of oxygen remains $\mathrm{Ti}_{\mathrm{Al}} \mathrm{O}$.

Results also show that these complex defects play a trapping role for $\mathrm{O}$ atoms that diffuse from one interstitial site to another. The impact of the presence of these traps on the diffusivity of $\mathrm{O}$ in TiAl was thus evaluated. Results show that $\mathrm{Ti}$ anti-sites significantly slow down oxygen diffusivity, particularly in $\mathrm{Ti}$ rich alloys.
Solutes can also reduce the $\mathrm{O}$ diffusivity but specifically in Al-rich alloys. For $\mathrm{Ti} / \mathrm{Al}>0.5$ ratios, the traps for $\mathrm{O}$ diffusion are mainly constituted by $\mathrm{Ti}$ anti-sites, and the addition of solutes does not contribute much to the trapping of diffusing $\mathrm{O}$ atoms. However, for $\mathrm{Ti} / \mathrm{Al}<0.5$ ratios, the contribution of solutes to the trapping phenomenon can be very strong, and reduce by 1-2 orders of magnitude the $\mathrm{O}$ effective diffusion coefficient, which is observed for temperatures around 800-1100 K. In conclusion, the choice of the solute elements and the $\mathrm{Ti} / \mathrm{Al}$ ratio both play a very important role in the design of the material as regards oxygen diffusion.

\section{ACKNOWLEDGMENTS}

This work was performed using HPC resources from CALMIP (Grant 2020-p0912 and 2021-p0912). This work was supported by the Occitanie Region and Safran Tech / Safran Group which are also acknowledged.
[1] M. Lamirand, J. Bonnentien, G. Ferrière, S. Guérin, J. Chevalier, Relative effects of chromium and niobium on microstructure and mechanical properties as a function of oxygen content in tial alloys, Scripta materialia (5) (2007) 325-328.

[2] M. Lamirand, J. Bonnentien, G. Ferrière, S. Guérin, J. Chevalier, Effects of interstitial oxygen on microstructure and mechanical properties of ti-48al-2cr-2nb with fully lamellar and duplex microstructures, Metallurgical and Materials Transactions A 37A (2006) 2369-2378.

[3] B. K. Kad, H. L. Fraser, Effects of oxygen on the deformation behaviour in single-phase $\gamma$-tial alloys, Philosophical Magazine Letters 70 (1994) 211-220.

[4] M. Morris, Dislocation mobility, ductility and anomalous strengthening of two-phase tial alloys: effects of oxygen and composition., Intermetallics 4 (1996) 417-426.

[5] A. Couret, An in-situ study of ordinary dislocation glide in $\gamma$-tial alloys., Philosophical Magazine A 79 (1999) 1977-1994.

[6] D. Caillard, M. Legros, A. Couret, Extrinsic obstacles and loop formation in deformed metals and alloys., Phil. Mag. 93 (2013) 203-221.

[7] S. Zghal, A. Menand, A. Couret, Pinning points anchoring ordinary and shockley dislocations in tial alloys, Acta Materialia 46 (16) (1998) 5899 - 5905. doi:https: //doi.org/10.1016/S1359-6454(98)00233-X.

URL http://www.sciencedirect.com/science/ article/pii/S135964549800233X

[8] J. Wiezorek, H. Fraser, Interaction of dislocations and interstitial solute in $\gamma$-tial., Philosophical Magazine A 77 (1998) 661-674.

[9] U. Messerschmidt, M. Bartsch, D. Haussler, M. Aindow, R. Hattenhauer, I. Jones, Mater. Res. Soc. Symp. Proc. 364 (1995) 47-52.

[10] W. Dowling, W. Donlon, The effect of surface film formation from thermal exposure on the ductility of ti-48al1v-0.2c., Scr. Metall. Mater. 27 (1992) 1663.
[11] C. Austin, T. Kelly, Structural intermetallics., TMS, Warrendale (1993).

[12] T. Kelly, C. Austin, P. Fink, J. Schaeffer, Effect of elevated temperature exposure on cast gamma titanium aluminide (ti-48al-2cr-2nb)., Scr. Metall. Mater. 30 (1994) 1105.

[13] S. Planck, A. Rosenberger, Gamma titanium aluminides., TMS, Warrendale (1999).

[14] S. Draper, B. Lerch, I. Locci, M. Shazly, V. Prakash, Effect of exposure on the mechanical properties of gamma met px., Intermetallics 13 (2005 1014.

[15] M. Thomas, O. Berteaux, F. Popoff, M. Bacos, A. Morel, B. Passilly, V. Ji, Effects of exposure at $700^{\circ} \mathrm{c}$ on rt tensile properties in a pm $\gamma$-tial alloy., Intermetallics 14 (2006) 1143.

[16] F. Appel, J. Paul, M. Oehring, Gamma titanium aluminide alloys., Wiley, Weinheim (2011).

[17] P. Sallot, J. Monchoux, S. Joulié, A. Couret, M. Thomas, Impact of $\beta$-phase in tial alloys on mechanical properties after high temperature air exposure., Intermetallics 119 (2020) 106729.

[18] A. Denquin, S. Naka, A. Huguet, A. Menand, Atomprobe investigation of the partitioning of interstitial elements in two-phase $\gamma+\alpha_{2}$ tial-based alloys., Scriptat Metallurgica et Materialia 28 (1993) 1131-1136.

[19] A. Menand, A. Huguet, A. Nérac-Partaix, Interstitial solubility in $\gamma$ and $\alpha_{2}$ phases of tial-based alloys, Acta Materialia 44 (12) (1996) 4729 - 4737. doi:https: //doi.org/10.1016/S1359-6454(96)00111-5. URL http://www.sciencedirect.com/science/ article/pii/S1359645496001115

[20] S. Draper, D. Isheim, Environmental embrittlement of a third generation $\gamma$ tial alloy, Intermetallics 22 (2012) 77-83.

[21] Y. Koizumi, M. Kishimoto, Y. Minamino, H. Nakajima, Oxygen diffusion in ti3al single crystals, Philosophical Magazine 88 (2008) 2991-3010. 
[22] A. Zalar, J. van Lier, E. J. Mittemeijer, J. Kovac, Interdiffusion at tio2/ti, tio2/ti3al and tio2/tial interfaces studied in bilayer structures,, Surface and Interface Analysis 34 (2002) 514-518.

[23] S. Kulkova, A. Bakulin, S. Kulkov, First-principles caluclations of oxygen diffusion in ti-al alloys., Latvian Journal of Physics and Technical Sciences 55 (2018) 20-29.

[24] D. Connétable, A. Prillieux, C. Thenot, J.-P. Monchoux, Theoretical study of oxygen insertion and diffusivity in the $\gamma$ tial 110 system, Journal of Physics: Condensed Matter (2020).

URL http://iopscience.iop.org/10.1088/ 1361-648X/ab6a2f

[25] A. V. Bakulin, S. Kulkov, S. Kulkova, Diffusion properties of oxygen in the $\gamma$-TiAl alloy., Journal of Experimental and Theoretical Physics 130 (2020) 579-590. doi:10.1134/S106377612003011.

URL https://doi.org/10.1134/S1063776120030115

[26] E. Epifano, G. Hug, First-principle study of the solubility and diffusion of oxygen and boron in $\gamma$-tial, Computational Materials Science 174 (2020) 109475. doi:https: //doi.org/10.1016/j.commatsci.2019.109475.

URL http://www.sciencedirect.com/science/ article/pii/S0927025619307748

[27] G. Kresse, J. Hafner, Ab initio molecular dynamics for liquid metals, Phys. Rev. B 47 (1993) 558-561. doi: 10.1103/PhysRevB.47.558.

URL https://link.aps.org/doi/10.1103/PhysRevB. 47.558

[28] G. Kresse, D. Joubert, From ultrasoft pseudopotentials to the projector augmented-wave method, Phys. Rev. B 59 (1999) 1758-1775. doi:10.1103/PhysRevB.59.1758. URL https://link.aps.org/doi/10.1103/PhysRevB. 59. 1758

[29] J. P. Perdew, K. Burke, M. Ernzerhof, Generalized gradient approximation made simple, Phys. Rev. Lett. 77 (1996) 3865-3868. doi:10.1103/PhysRevLett.77.3865. URL https://link.aps.org/doi/10.1103/ PhysRevLett.77.3865

[30] H. J. Monkhorst, J. D. Pack, Special points for brillouinzone integrations, Phys. Rev. B 13 (1976) 5188-5192. doi: 10.1103/PhysRevB.13.5188.

URL https://link.aps.org/doi/10.1103/PhysRevB. 13.5188

[31] R. Besson, Point defects in multicomponent ordered alloys: Methodological issues and working equations, Acta Materialia 58 (2) (2010) 379 - 385. doi:https: //doi.org/10.1016/j.actamat.2009.09.014.

URL http://www.sciencedirect.com/science/ article/pii/S1359645409006107

[32] A. Van der Ven, G. Ceder, Vacancies in ordered and disordered binary alloys treated with the cluster expansion, Phys. Rev. B 71 (2005) 054102. doi:10.1103/PhysRevB. 71.054102 .

URL https://link.aps.org/doi/10.1103/PhysRevB. 71.054102

[33] R. Besson, A. Legris, J. Morillo, Comprehensive ab initio thermodynamic treatment of impurities in ordered alloys: Application to boron in b 2 fe-al, Phys. Rev. Lett. 89 (2002) 225502. doi:10.1103/PhysRevLett.89.225502.

[34] R. Besson, A. Legris, J. Morillo, Influence of complex point defects in ordered alloys: An ab initio study of b2 fe-al-b, Phys. Rev. B 74 (2006) 094103. doi:10.1103/ PhysRevB.74.094103.
URL https://link.aps.org/doi/10.1103/PhysRevB . 74.094103

[35] R. Besson, A. Legris, D. Connetable, P. Maugis, Atomicscale study of low-temperature equilibria in iron-rich alc-fe, Phys. Rev. B 78 (2008) 014204. doi:10.1103/ PhysRevB.78.014204.

URL https://link.aps.org/doi/10.1103/PhysRevB. 78.014204

[36] R. Besson, L. Favergeon, Understanding the mechanisms of cao carbonation: role of point defects in caco 3 by atomic-scale simulations, The Journal of Physical Chemistry C 118 (39) (2014) 22583-22591.

[37] D. Gryaznov, E. Blokhin, A. Sorokine, E. A. Kotomin, R. A. Evarestov, A. Bussmann-Holder, J. Maier, A comparative ab initio thermodynamic study of oxygen vacancies in zno and srtio3: Emphasis on phonon contribution, The Journal of Physical Chemistry C 117 (27) (2013) 13776-13784. arXiv:https://doi.org/10.1021/ jp400609e, doi:10.1021/jp400609e.

URL https://doi.org/10.1021/jp400609e

[38] C. Woodward, S. Kajihara, L. H. Yang, Site preferences and formation energies of substitutional si, nb, mo, ta, and w solid solutions in $L 1_{0}$ ti-al, Phys. Rev. B 57 (1998) 13459-13470. doi:10.1103/PhysRevB.57.13459.

URL https://link.aps.org/doi/10.1103/PhysRevB. 57.13459

[39] D. Connétable, Theoretical study on hydrogen solubility and diffusivity in the $\gamma$-tial $L 1_{0}$ structure, International Journal of Hydrogen Energy 44 (2019) 1221512227. doi:https://doi.org/10.1016/j.ijhydene. 2019.03.110.

[40] C. Herzig, T. Przeorski, Y. Mishin, Self-diffusion in $\gamma$-tial: an experimental study and atomistic calculations, Intermetallics 7 (3) (1999) 389 - 404. doi:https: //doi.org/10.1016/S0966-9795(98)00117-4.

URL http://www.sciencedirect.com/science/ article/pii/S0966979598001174

[41] Y. Mishin, C. Herzig, Diffusion in the $\mathrm{Ti}-\mathrm{Al}$ system, Acta Materialia 48 (3) (2000) 589-623. doi:10.1016/S1359-6454(99)00400-0.

URL https://link.aps.org/doi/10.1016/ S1359-6454 (99) 00400-0

[42] Y. Hao, R. Yang, Y. Song, Y. Cui, D. Li, M. Niinomi, Formation of point defects in tial and nial, Intermetallics 12 (7-9) (2004) 951-956. doi:10.1016/j. intermet.2004.02.025.

[43] A.V. Bakulin, S.E. Kulkova; Effect of impurities on the formation energy of point defects in the $\gamma$-TiAl alloy, Journal of Experimental and Theoretical Physics, 127 (6) (2018) 1046-1058. doi:10.1134/S1063776118120130. URL https://link.aps.org/doi/10.1134/ S1063776118120130

[44] C. Woodward, S. Kajihara, Density of thermal vacancies in $\mathrm{g}$-ti-al- $\mathrm{m}, \mathrm{m}=\mathrm{si}, \mathrm{cr}, \mathrm{nb}, \mathrm{mo}$, ta or $\mathrm{w}$, Acta Materialia 47 (14) (1999) 3793-3798. doi:https: //doi.org/10.1016/S1359-6454(99)00231-1.

URL https://www.sciencedirect.com/science/ article/pii/S1359645499002311

[45] U. Brossmann, R. Würschum, K. Badura, H.-E. Schaefer, Thermal formation of vacancies in tial, Phys. Rev. B 49 (1994) 6457-6461. doi:10.1103/PhysRevB.49.6457. URL https://link.aps.org/doi/10.1103/PhysRevB . 49.6457 
[46] H. E. Schaefer, K. Badura-Gergen, Systematics of thermal defect formation, migration and of self-diffusion in intermetallic compounds, in: Defect and Diffusion Forum, Vol. 143, Trans Tech Publ, 1997, pp. 193-208.

[47] S. Huang, Structural intermetallics, TMS (R. Dariola, J. J. Lewandowski, C. T. Liu, P. L. Martin, D. B. Miracle, and M. V. Nathal) Champion, Pennsylviania (1993).

[48] C. Jiang, First-principles study of site occupancy of dilute $3 \mathrm{~d}, 4 \mathrm{~d}$ and $5 \mathrm{~d}$ transition metal solutes in 110 tial, Acta Materialia 56 (20) (2008) 6224-6231. doi:https: //doi.org/10.1016/j.actamat.2008.08.047.

URL https://www.sciencedirect.com/science/ article/pii/S1359645408006071

[49] Y. Hao, D. Xu, Y. Cui, R. Yang, D. Li, The site occupancies of alloying elements in tial and ti3al alloys, Acta Materialia 47 (4) (1999) 1129-1139. doi:https: //doi.org/10.1016/S1359-6454(99)00006-3.

URL https://www.sciencedirect.com/science/ article/pii/S1359645499000063
[50] R. Oriani, The diffusion and trapping of hydrogen in steel, Acta Metallurgica 18 (1) (1970) 147-157. doi: https://doi.org/10.1016/0001-6160(70)90078-7. URL https://www.sciencedirect.com/science/ article/pii/0001616070900787

[51] R. Kirchheim, Monte-carlo simulations of interstitial diffusion and trapping - i. one type of traps and dislocations, Acta Metallurgica 35 (2) (1987) 271-280. doi: https://doi.org/10.1016/0001-6160(87)90235-5. URL https://www.sciencedirect.com/science/ article/pii/0001616087902355

[52] Y. Wang, D. Connétable, D. Tanguy, Influence of trap connectivity on $\mathrm{h}$ diffusion: Vacancy trapping, Acta Materialia 103 (2016) 334-340. doi:https: //doi.org/10.1016/j.actamat.2015.10.018. URL https://www.sciencedirect.com/science/ article/pii/S1359645415300185 